\title{
name \\ Applications of Phyto-Nanotechnology for the Treatment of Neurodegenerative Disorders
}

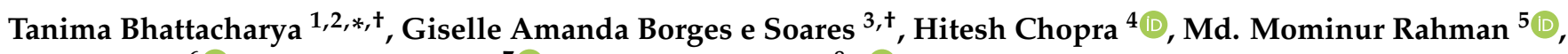 \\ Ziaul Hasan ${ }^{6}\left(\mathbb{D}\right.$, Shasank S. Swain ${ }^{7}\left(\mathbb{1}\right.$ and Simona Cavalu ${ }^{8, *}$
}

Citation: Bhattacharya, T.; Soares, G.A.B.e.; Chopra, H.; Rahman, M.M.; Hasan, Z.; Swain, S.S.; Cavalu, S. Applications of Phyto-Nanotechnology for the Treatment of Neurodegenerative Disorders. Materials 2022, 15, 804. https://doi.org/10.3390/ma15030804 Academic Editor: Alina Maria Holban

Received: 18 December 2021

Accepted: 18 January 2022

Published: 21 January 2022

Publisher's Note: MDPI stays neutral with regard to jurisdictional claims in published maps and institutional affiliations.

Copyright: (C) 2022 by the authors. Licensee MDPI, Basel, Switzerland. This article is an open access article distributed under the terms and conditions of the Creative Commons Attribution (CC BY) license (https:// creativecommons.org/licenses/by/ $4.0 /)$.
1 Innovation, Incubation \& Industry (i-cube) Laboratory, Techno India NJR Institute of Technology, Udaipur 313003, India

2 Department of Science \& Engineering, Novel Global Community Educational Foundation, Hebersham, NSW 2770, Australia

3 Department of Medicinal and Biological Chemistry, University of Toledo, 3000 Arlington Ave., Toledo, OH 43614, USA; giselleamanda.borgesesoares@rockets.utoledo.edu

4 Department Pharmacology, Chitkara College of Pharmacy, Chitkara University, Punjab 140401, India; chopraontheride@gmail.com

5 Department of Pharmacy, Faculty of Allied Health Sciences, Daffodil International University, Dhaka 1207, Bangladesh; mominur.ph@gmail.com

6 Department of Biosciences \& Centre for Interdisciplinary Research in Basic Sciences, Jamia Millia Islamia, Jamia Nagar, New Delhi 110025, India; zhasan.biochem@gmail.com

7 Division of Microbiology and NCDs, ICMR-Regional Medical Research Center, Chandrasekharpur, Bhubaneshwar 751023, India; swain.shasanksekhar86@gmail.com

8 Faculty of Medicine and Pharmacy, University of Oradea, 410087 Oradea, Romania

* Correspondence: btanima1987@gmail.com (T.B.); simona.cavalu@gmail.com (S.C.)

$\dagger$ These authors contributed equally to this work.

\begin{abstract}
The strategies involved in the development of therapeutics for neurodegenerative disorders are very complex and challenging due to the existence of the blood-brain barrier (BBB), a closely spaced network of blood vessels and endothelial cells that functions to prevent the entry of unwanted substances in the brain. The emergence and advancement of nanotechnology shows favourable prospects to overcome this phenomenon. Engineered nanoparticles conjugated with drug moieties and imaging agents that have dimensions between 1 and $100 \mathrm{~nm}$ could potentially be used to ensure enhanced efficacy, cellular uptake, specific transport, and delivery of specific molecules to the brain, owing to their modified physico-chemical features. The conjugates of nanoparticles and medicinal plants, or their components known as nano phytomedicine, have been gaining significance lately in the development of novel neuro-therapeutics owing to their natural abundance, promising targeted delivery to the brain, and lesser potential to show adverse effects. In the present review, the promising application, and recent trends of combined nanotechnology and phytomedicine for the treatment of neurological disorders (ND) as compared to conventional therapies, have been addressed. Nanotechnology-based efforts performed in bioinformatics for early diagnosis as well as futuristic precision medicine in ND have also been discussed in the context of computational approach.
\end{abstract}

Keywords: nanomedicine; nanoparticles; phytomedicine; bioinformatics; neurodegenerative diseases

\section{Introduction}

Nanotechnological advancements in neurological science are projected to have a significant effect on the development of novel therapeutical strategies. The capability to produce nanoparticles in the same size domain as proteins has led to a wide range of applications in the biomedical field, as they can invigorate, respond to, and affect target cells and tissues to ensure the desired physiological reactions while diminishing undesirable results. In addition, nanotechnology can permit a more exact and ideal control of complex natural frameworks than customary pharmacological methodologies can, for example, the 
blood-mind obstruction (BBB). "Neurodegenerative diseases" (NDs) refers to a gathering of discontinuous or potentially familial conditions portrayed by the deficiency of neuronal subtypes over a long period. Alzheimer's disease (AD) and Parkinson's disease (PD) are amongst the most decimating illnesses of the twenty-first century [1-6].

Around 24 million individuals overall experience the ill-effects of dementia, with Alzheimer's sickness representing 60\% of cases [7]. Learning and memory issues occur in Alzheimer's patients. Net cerebral decay, which demonstrates the deficiency of neurons and the presence of various neuronal extracellular plaques and intracellular neurofibrillary tangles, has been found in post-mortem examinations of human brain tissue, fundamentally in the front-facing and transient flaps, including the hippocampus [8]. Notwithstanding, although the pathophysiology of AD is known, the reason for which it occurs, and its trigger, is unknown. As a result, AD treatment is only based on symptomatic treatment of the disease. The degeneration of nigrostriatal dopaminergic neurons in the midbrain causes extreme side effects including hypokinesia, bradykinesia, unbending nature, and a resting quake [9].

Although Parkinson's disease (PD) is the second most prevalent chronic and progressive non-degenerative illness (ND), it has an enormous social and economic effect on the great majority of people affected by it [10]. The ventral tegmental region and the substantia nigra of the brain produce less dopamine (DA) when dopamine neurons degenerate over time. Patients with Parkinson's disease (PD) may have a wide range of symptoms including stiffness, tremor, and slowness of movement. In certain cases, it may be difficult to tell the difference between Parkinson's disease and other conditions that have many of the same symptoms. As a result, the word "Parkinsonism" has come to describe a wide range of neurological conditions. Symptoms of Parkinsonism fall into two categories: primary and secondary. Idiopathic Parkinsonism, the most common kind of primary Parkinsonism, has no recognised aetiology. A variety of conditions may lead to secondary Parkinsonism, including progressive supranuclear palsy, multiple system atrophy, and others, the most frequent of which is drug-induced Parkinsonism following cerebrovascular illness. Vascular Parkinsonism is a distinct clinical entity that falls under the umbrella of Parkinsonism, although it has a variable natural history and a wide range of clinical manifestations. In addition, there is strong evidence for inclusion of clock genes in PD [10].

Dopamine agonists, such as levodopa, are currently utilized as first-line treatment for PD. However, as the disease advances, patients become less receptive to levodopa and disease progression continues. Profound mind incitement and foetal dopamine neuron transplantation have been examined as options in contrast to pharmacological consideration [11,12]. These medicines are currently suggestive, and do not appear to have the option to stop or counteract the progressing consumption of dopaminergic neurons [13-15]. Medication conveyance to the cerebrum remains a significant test in the treatment of AD and PD. The rise of new, useful treatment modalities for the treatment of NDs is an intriguing issue of examination at the present time [16]. Considering the various defensive hindrances that encompass the CNS, the development of effective therapeutics to treat patients with NDs is of crucial significance.

There are microvascular endothelial cells that line the cerebral capillaries of most mammals and other species with a well-developed CNS, which the BBB is composed of. Based on an average microvessel surface area of $150-200 \mathrm{~cm}^{2}$ per $\mathrm{g}$ of tissue, it is anticipated that a normal adult has a total surface area of $12-18 \mathrm{~m}^{2}$ [4]. The BBB serves as a barrier between the bloodstream and the central nervous system, protecting the brain's parenchyma from exposure to potentially harmful substances carried by the bloodstream. Specialized ion channels and transporters combine in the BBB to keep the ionic composition optimal for neuronal and synaptic signalling processes. Potassium concentrations in the CSF and ISF, for example, are 2.5-2.9 mM. The plasma potassium concentration is $4.5 \mathrm{mM}$, regardless of whether the fluctuations are induced by illness or imposed artificially. Calcium, magnesium, and $\mathrm{pH}$ are all controlled by the BBB [17]. Neuronal excitability and macrophage movement across the BBB are regulated by calcium and potassium homeostasis [18]. 
The BBB's limitation and the medication discharge energy that trigger fringe results are two significant realities about neurotherapeutics. Despite the prevalent attitude, it is presently realized that NDs can be multisystemic in nature, which represents different difficulties for future consideration. A course of a few harmful atomic and cell occasions, instead of a solitary pathogenic factor, causes the demise of specific kinds of neurons in NDs. Accordingly, nanotechnology can offer an expected answer for a significant number of these difficulties in the treatment of AD and PD by considering specific medication conveyance and improving the bioavailability as well as the viability of different medications and other bioactive specialists utilized in NDs [19].

\section{Materials and Methods}

Relevant studies pertaining to the applications of nanotechnology for CNS-based disorders were selected through algorithm application according to the recommendations of Page et al. [20,21]. Literature search was performed based on several scientific databases such as Google Scholar (http:/ / www.scholar.google.co.in) (accessed on 10 November 2021), PubMed (http: / / www.ncbi.nlm.nih.gov/pubmed) (accessed on 10 November 2021), Elsevier (https:/ / www.elsevier.com/en-in), ScienceDirect (http:/ / www.sciencedirect.com) (accessed on 10 November 2021), Springer (http:/ / www.springer.co.in) (accessed on 10 November 2021), and Scopus (http: / / www.scopus.com) (accessed on 10 November 2021). Only publications that had the full text available and book chapters restricted to the English language were reviewed, and figures were created using Biorender.com. (accessed on 10 November 2021).

\section{Real Problem of Neurodegenerative Disease}

Numerous neurodegenerative sicknesses such as AD, PD, Huntington's disease, and amyotrophic horizontal sclerosis (ALS), are connected to ageing. These neurodegenerative infections are critical social issues in numerous nations as the populace ages. The collection of misfolded and totalled proteins in the mind is an ordinary neurotic aggregate in these illnesses, as is shown in Figure 1. A developing assortment of proof demonstrates that poisonous protein conglomeration and neurodegenerative infections are connected. Revelatory endeavours for sickness-changing therapeutics have lately significantly expanded, because of a more noteworthy comprehension of the pathogenesis of these infections [22].

\section{NEURODEGENERATIVE DISEASES AND TYPES OF NEURONS AFFECTED}

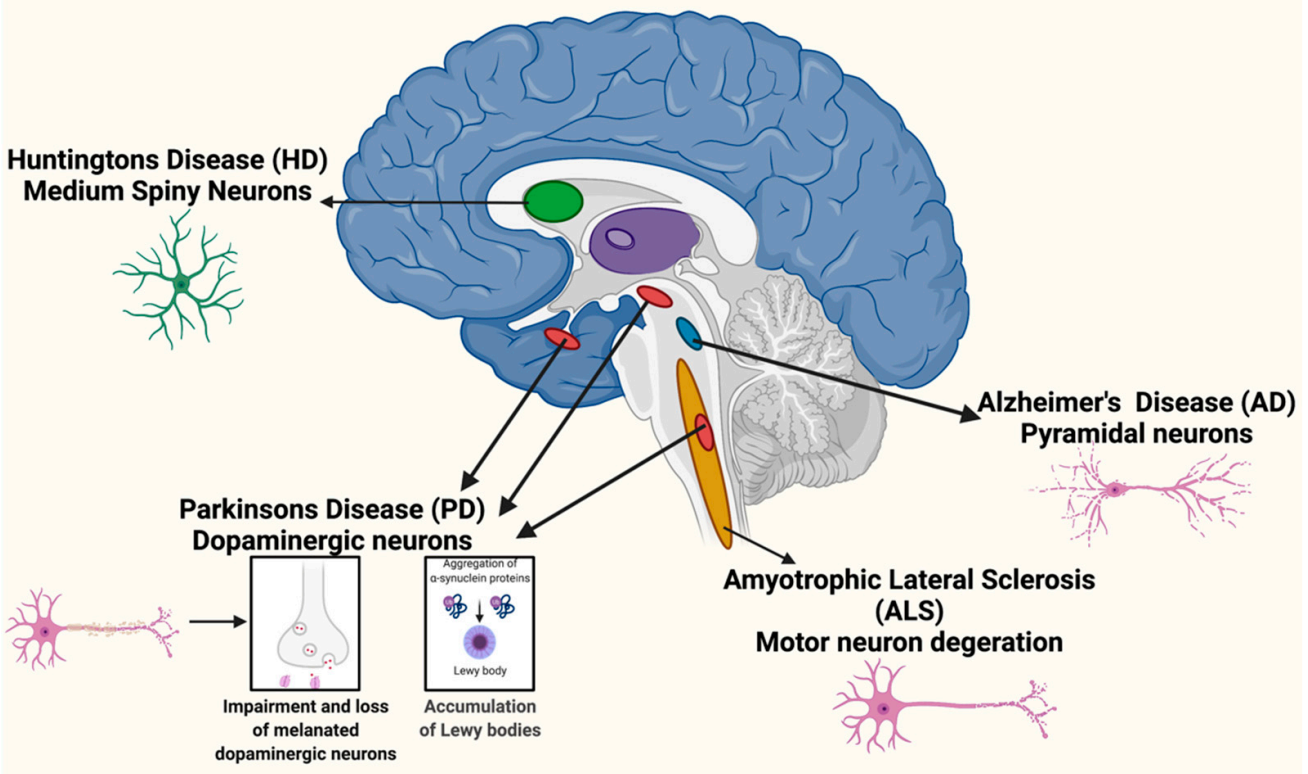

Figure 1. Neurodegenerative diseases and the types of neurons affected. 
Neurodegenerative diseases are now the most common and debilitating illnesses afflicting humans. They have recently surpassed cancer, myocardial infraction (cardiovascular disorders), and stroke as the fourth leading cause of death. Neurodegenerative disorders disrupt a person's reasoning, skilled gestures, emotions, cognitive actions, and memory, causing short- and long-term disabilities.

\section{Role of Nanotechnology in Neurodegenerative Disorders}

Neurodegenerative disorders are a collection of neurological illnesses that damage the brain or spinal cord's neuronal structure and function. Because of the ageing population and the increasing prevalence of CNS disorders including Alzheimer's, Parkinson's, and strokes, the healthcare industry is faced with a tremendous issue. Early identification and treatment of CNS illnesses are still difficult despite advancements in our knowledge of their pathophysiology, and current medications are focused mostly on treating their symptoms. Due to unsatisfactory pharmacokinetics and unspecific targeting of new medications (such as proteins and peptides) that have been developed, many of these new treatments may not succeed because they may raise the risk of side effects. Biological barriers, such as the blood-brain barrier (BBB), are at the root of these difficulties. As a barrier between the CNS and peripheral circulation, it blocks the transfer of most chemicals from the blood to the brain [23]. In order to prevent chemicals, ions, and cells from crossing from the bloodstream into the central nervous system, BBB is made up of endothelial cells, astrocyte end-feet, and pericytes. The five primary ways by which chemicals traverse the BBB are diffusive transcellular lipoid bilayer membrane transport; transport carriers; specific receptor-mediated endocytosis and transcytosis; adsorptive transcytosis; and paracellulartight junction transport. Toxins, infections, and inflammation are all prevented, and the CNS's homeostasis is maintained, due to the presence of BBB [24]. Drug transport to the central nervous system (CNS) was further hindered by the BBB's restrictive character. Furthermore, BBB malfunction has been reported in the majority of CNS illnesses, including Alzheimer's, Parkinson's, and strokes. Although it is unclear whether BBB failure is the primary cause of illness development, alterations in the transport system and enzymes are a significant contributor and exacerbator [24]. In CNS illnesses, the BBB impairment has major consequences for therapy. CNS illness patients may benefit from having an intact blood-brain barrier (BBB). In light of the fact that BBB malfunction plays a critical role in developing illness, this will undoubtedly be a divisive approach.

Nanotechnology, on the other hand, has advanced quickly in recent years and may offer significant benefits for the detection and treatment of CNS illnesses. Control or manipulation of nanometre-scale (one billionth of a metre) designed materials or devices is what is meant by the term "nanotechnology" [25]. Due to changes in the arrangement and spacing of surface atoms and molecules, nanomaterials exhibit markedly different characteristics than their macroscale counterparts [26].

There are several applications for biomarker discovery, treatments, and theranostics using nanomaterial-based technologies. To begin with, nanomaterials that have been changed may be utilised to identify and treat damaged cells and tissues at the molecular level. When a surface that has been modified with unique molecules, nanoengineered materials may also maintain medication release, boost bioavailability, distribute numerous agents, and preserve substances from degradation. Surface functionalization of nanomaterials may be used to target and infiltrate the BBB while also lengthening the nanomaterial's blood half-life. For CNS illness diagnosis and treatment, nanomaterials are at the top of the list because of their unique features.

There are many promising advantages to be gained from using nanoparticles in the medical field, such as a high drug-loading capacity, which reduces the risk of chemical interactions or toxicity; a high surface area-to-volume ratio, which makes it easier to administer parenterally; the ability to use active and passive drug-targeting strategies; and sustained and continuous dosing options. Nanoparticle size, targeting properties, lipid, or water solubility and their respective hydrophobicity or hydrophilicity, chemical 
and physical stability, surface charge, and permeability, biodegradability, biocompatibility, cytotoxicity, drug release profile and antigenicity of the final product all play a role in the selection of the nanoparticle manufacturing materials.

NPs may be used for brain medication delivery because of their multifunctional and adaptable architectures. However, several factors must be considered before they may be used, including surface chemistry, hydrophobicity, shape, size, and charge, to name a few. Biocompatibility, decreased toxicity, and the capacity to bind and transport medications or therapies are all desirable features of an ideal NP. As long as it does not degrade quickly in vivo, it can pass across the BBB and regulate the release of medicines for extended periods of time. All of these characteristics result in NPs that are very effective at penetrating the BBB [27]. An investigation into site-specific drug delivery has resulted in a non-invasive distribution of the given dosage to specified areas, allowing for a precise and concentrated administration of the therapeutic dose at the site of the pharmacological activity. There are now non-invasive approaches, such as intranasal administration using drug modification to increase BBB permeability [28] as well as invasive ones, such as intraventricular or intracerebral injection or implantation, and infusion [29]. Disruption may also be effective in certain cases to cross the BBB [30]. The rupture of the BBB is often employed to improve the efficiency of medication transport to the brain. Mannitol, for example, is used to open the $\mathrm{BBB}$ to treat some CNS malignancies, and ultrasound is used to create temporary holes in the BBB [31]. Small therapeutic compounds (less than $1000 \mathrm{Da}$ ) have recently been shown to be able to pass across the BBB in Alzheimer's disease (AD) and multiple sclerosis (MS) [32]. Physical and chemical features of NPs determine their path across the BBB and the methods by which they may cross it [33]. It is possible for NPs to penetrate the BBB and distribute medications in the sick brain when they are functionalized with a suitable ligand [34,35]. Endothelial cells may be crossed via transcytosis, allowing medications or drug-conjugated NPs to enter the central nervous system [36]; endothelial cells can be entered by endocytosis, allowing pharmaceuticals to cross the blood-brain barrier [37]. Researchers in neuropharmaceuticals are working to understand the processes of receptormediated and adsorptive transcytosis, as well as all the inherent physicochemical features of neuropharmeuticals. As a result, this might lead to new therapies that are more effective in crossing the blood-brain barrier (BBB) [38].

\subsection{Techniques for Preparation of Nanoparticles and Nanocapsules \\ 4.1.1. Nanoprecipitation}

Colloidal drug delivery devices may be integrated with active substances using the nanoprecipitation technique pioneered by Fessi et al. [39]. Some of the benefits of the generated nanoparticles include controlled release, targeted distribution, and better stability in biological fluids. As a result, you may expect minimal toxicity and moderate side effects. Preparing nanoparticles by nanoprecipitation requires a good solvent (usually an organic solvent such as ethanol, isopropanol, or acetone), whereas the particle is created using a nonsolvent (such as water). Nanoprecipitation relies on both an organic and non-solvent phase, often referred to as aqueous phase, to guarantee that all initial components are completely soluble. The organic phase might include a low HLB surfactant and active compounds dissolved in an organic solvent or a mixture of organic solvents. The solubility of the active molecule in the solvent is one of the factors limiting the amount of medicine that can be loaded onto the particle. Particle formation and physical stability are made easier in the non-solvent phase by water-soluble stabilizing compounds [40]. There have been reports of particles devoid of stabilizing compounds. The amphiphilic nature of isoprenoid chains allows them to be linked to the active molecule in this situation. Nanoparticles form when the organic component is abruptly dumped or mixed with the aqueous phase. Particle size and polydispersity index are unaffected by nanoprecipitation, which is a reliable process. Instead, it seems that the features of the nanosized system are determined by parameters connected with the formulation used [40]. This might be linked to the procedures proposed for the production of nanoprecipitation particles. Nano and submicron particles can only 
be formed when particular polymer/solvent/nonsolvent ratios are used. As a consequence of the Gibbs-Marangoni effect (interfacial turbulence and thermal inequalities produced by mutual miscibility of the solvent and non-solvent and their varying interfacial tensions), mechanical mixing breaks down the organic phase into drops inside the aqueous phase [41]. Submicron-sized droplets of organic solvent diffuse away, causing the material that causes particle precipitation to become insoluble. It has also been suggested that the "ouzo effect", which relies on the system's chemical instability, might be a mechanism. In this situation, when aqueous and organic phases are joined, particle-forming molecules are supersaturated, allowing for the generation of "protoparticles" that follow the classic nucleation-and-growth process. Work circumstances must be created in order to enable the spontaneous generation of submicron or nanoscale particle sizes with the lowest polydispersity indices. As nanoprecipitation is difficult to standardize, polymer aggregation results in a wide and asymmetric particle size ranges. Low stabilizing agent concentrations and poor phase mixing are two obvious signs of polymer aggregates: a concentrated organic phase and a high organic phase ratio $[40,42]$.

\subsubsection{Emulsification-Diffusion Method}

So-called spontaneous emulsion diffusion describes a method for making biodegradable nanoparticles by dissolving a polymer in a mixture of water-immiscible and water-miscible solvents (such as dichloromethane) [43]. The quick dissolving of the miscible solvent causes the formation of a nanoemulsion when this solution is introduced to water. Immiscible liquid evaporates, forming nanoparticles. Nanoemulsions may be created by turbulence produced during solvent displacement, and there is no actual diffusion stage in the process of creating them. Solvent displacement and solvent evaporation are combined in this procedure, making it a hybrid. Due to the use of solely miscible solvents, the modified spontaneous emulsification solvent technique is obviously a method of solvent displacement [44].

The technique used to produce diffusion is a key variable in the emulsion diffusion approach. Because dilution water is added, low-solids dispersions are formed. So, armed with this information, it was suggested that the solvent (with a low boiling point) from the internal phase be extracted and then distilled directly into the exterior phase [45]. Due to the saturation of the continuous aqueous phase, its rapid displacement will prompt a free flux of the solvent globules to generate an anti-solvent medium, where the material will aggregate in the form of nanoparticles, in such a way that high solid concentrated dispersions (up to $30 \%$ ) can be prepared from different materials such as polymers (e.g., poly(D,L-lactic acid), poly(!-caprolactone), and other materials. By using an emulsification-diffusion method, Yusuf et al. developed an emulsification solvent diffusion technique for coating with PS80 that reduced SOD1 levels and immobility, while raising acetylcholinesterase levels in Piperine-SLNs produced with Piperine. In addition, histological investigation revealed decreased plaques and tangles [46].

\subsubsection{Double Emulsion Technique}

The most popular techniques for evaporating solvent from emulsions are the singleand double-emulsion procedures. This process uses an organic phase that has been emulsified in an aqueous medium with surfactants or stabilisers before the solvent is evaporated to create the NP [47]. Double emulsion solvent technique uses a three-phase process, which is different from the single emulsion solvent method, which uses just two phases. Shear stress during the homogenization process is the fundamental downside of these two methods, which results in poor protein encapsulation effectiveness. The nanoprecipitation approach may help overcome this issue. Dropwise addition to the aqueous media of the organic solvent containing PLGA results in the fast diffusion of the miscible solvent, resulting in the creation of the NPs layer-by-layer method [48].

Sukhorukov et al. devised the approach for the production of vesicular particles. Adsorbed polymer layers may be applied to a colloidal template using either the polymer solution and washing or the addition of a miscible solvent to reduce polymer solubility. Chi- 
tosan, heparin, polylysine, protamine sulfurate, gelatine, and dextran sulphate are examples of common polymers that may have polyanionic or polycationic characteristics $[49,50]$.

\subsection{Green Method of Synthesis of Nanoparticles}

Research and development in materials science and technology is entering a new phase in which "green synthesis" methodologies and technologies are becoming more popular. A major benefit to environmentally friendly synthesis of materials and nanomaterials will be improved by regulation, control, clean-up, and remediation of the production process.

'Green synthesis' is necessary in order to prevent the generation of undesirable or dangerous by-products via the development of dependable, long-lasting, and environmentally friendly synthesis methods. In order to attain this purpose, it is critical to make use of appropriate solvent systems and natural resources. The use of metallic nanoparticles in the green synthesis of biological materials has been widely accepted (e.g., bacteria, fungi, algae, and plant extracts). Using plant extracts to synthesise metal and metal oxide nanoparticles is one of the more straightforward green synthesis techniques accessible, especially when compared to bacteria- and fungus-mediated approaches. Biogenic nanoparticles are a grouping of these compounds.

Various reaction factors, such as solvent, temperature, pressure, and $\mathrm{pH}$ conditions, influence green synthesis methods based on biological precursors (acidic, basic, or neutral). Many plant extracts, particularly those from leaves, include potent phytochemicals, such as ketones, aldehydes, flavonoids, amides and terpenoids, carboxylic acids, phenols and ascorbic acids, that may be used to synthesize metal and metal oxide nanoparticles $[51,52]$.

\section{Role of Phyto-Nanomedicine on Neurodegenerative Diseases Treatment}

Neurodegenerative Diseases (ND) are basically disorders related to age and are prevailing rapidly worldwide due to the increased elderly population in recent years. The actual problem however is not the increasing prevalence but the lack of effective treatment. As per published evidence from the past, NDs were discovered in the early 1900s, however, presently, no effective treatments for these disorders are found in modern society. Integrative medicine can sometimes delay the progression of these diseases or exhibit protective effects. It is believed by scientists that with the development of integrative medicine and modern science, the former will progressively take a more and more significant role in the treatment of ND [52,53].

A series of synthetic drugs have shown positive results for the treatment of some common NDs including Autism, PD, AD, and other chronic illnesses. The use of synthetic drugs is associated with many side effects, which make them inappropriate for regular treatment. Considering the adverse effects of these synthetic drugs, scientists have made a soft turn towards the utilization of phytochemicals, as they have minimal side effects. The antioxidative, anticholinesterase, anti-inflammatory, and anti-amyloid properties of phytochemicals makes phytochemicals a promising therapeutic agent $[54,55]$.

In consideration that current therapeutics seem to be inadequate treatment for the above-mentioned disorders, scientists are exploring their options with plant-based drugs using nanotechnological approaches. Nanotheranostics is one such approach which is gaining wide attractions from the scientific community at a global level for the treatment of ND. It uses nanoparticles for the simultaneous diagnosis as well as for treatment. Research findings of Tripathi et al. [56] reveal that this treatment has been receiving significance in the medical field because it is extremely aggressive and specifically targets the affected area. Moreover, alterations with respect to type of disease and personalization based on the needs of the patient can be met, which further increases the applicability of the approach [57]. A novel nanotheranostic system has been developed by chemical engineers, which uses adjustable light that activates nanoparticles and opens new applicability in the field [58].

In the subsequent sections we will discuss in detail the various types of plant-based medicines that are utilized in ND treatments along with the conventional approaches and recent trends in the plant-derived nanomedicine discovered so far. 


\subsection{Types of Phyto-Medicines Available for Treatment}

\section{- Acorus calamus}

Acorus calamus, also commonly referred to as sweet flag, belongs to the family Acoraceae and acts as a nervous system rejuvenator and has beneficial effects on the brain through memory enhancement, learning behaviour, and performance modification. Acorus calamus consists of a majority of $\alpha$-and $\beta$-asarone while $\beta$-asarone brings about the suppression of beta-amyloid-induced neuronal apoptosis observed in the hippocampus through the downregulation of Bcl-w and Bcl-2, which further causes the activation of caspase-3 and phosphorylation of c-Jun N-terminal kinase (JNK). Apart from the abovementioned benefits parts, of Acorus calamus also showed an inhibitory result on AChE with an IC50 value of $188 \mu \mathrm{g} / \mathrm{mL}$. It has also shown positive results by improving the dopaminergic nerve function, and thus acts as neuroprotective for PD [59].

\section{- Allium sativum}

Allium sativum, commonly known as garlic, belongs to the family Amaryllidaceae and has been used since ancient times for its medicinal properties. It was used for cardiovascular disease as well as for the prevention and treatment of other metabolic diseases such as hyperlipidemia, atherosclerosis, thrombosis, dementia, hypertension, diabetes, and cancer. S-allyl cysteine (SAC), one of the major constituents found in aged garlic extract (AGE), has been extensively studied. SAC has indirect and direct antioxidant activity. Besides bringing about a decrease in lipid peroxidation and DNA fragmentation, it also causes a reduction in oxidation and nitration. In the Parkinsonian models, namely 1-methyl-4-phenyl pyridinium (MPP) and 6-hydroxydopamine (6-OHDA), SAC causes a protection of dopamine levels, prevents oxidative damage and causes peroxidation of lipids. [60].

\section{- Bacopa monnieri}

Bacopa monnieri (Linn), popularly called "Brahmi" (family Scrophulariaceae), is a herb found in tropical countries such as India. Steroidal bacosides (A and B) and saponins are the main active compounds present in Bacopa monnieri. These active compounds are responsible for enhancing memory and learning. Other constituents include bacopa saponins F, E, and D, flavonoids, phytosterols, and alkaloids. Superoxide SOD, CAT, GPx, and glutathione reductase (GSR) activity is enhanced by Bacoside A. Therefore, the levels of glutathione in the brain are upregulated significantly. Bacoside A inhibits lipid peroxidation by modifying the activity of enzymes such as Hsp 70 and cytochrome P450 in the brain. It also improves the activities of adenosine triphosphatases (ATPases), maintains ionic equilibrium, and restores level of selenium and zinc in the brain. The reduction in aggregation of alpha-synuclein protein by Bacopa monnieri was also found by researchers [61].

\section{- Centella asiatica}

Centella asiatica belonging to the Apiaceae (Umbelliferae) family and has been demonstrated to possess a neuroprotective property. Since ancient times, it was part of the Ayurvedic system as an alternative medicine for bringing about memory improvement. Centella asiatica decreases $\mathrm{A} \beta$ deposition in the brain, exhibits potent antioxidant activity and can scavenge free radicals, causes a reduction in ferric ions, and brings about a restoration of GSH levels through an upregulation of glutathione-S-transferase activity. Chen et al. [62] carried out a study which suggested that Centella asiatica ethanolic extract causes the suppression of $A \beta$-induced neurotoxicity through the enhancement of the antioxidative-based defence system in IMR32 and PC12 differentiated cells. Amelioration of decrease in $\mathrm{AChE}$ activity due to colchicine-induction, neuronal damage through induction of asiaticoside occurring through nitric oxide inhibition, also reflects the neuroprotective effect of Centella asiatica [63].

\section{- Curcuma longa}

Turmeric, derived from the plant Curcuma longa, belonging to the Zingiberaceae family, is a gold-coloured spice and has been used traditionally as medicine for a variety of 
diseases $[64,65]$. Curcumin, turmeric's principal constituent, has several known neuroprotective actions. In patients afflicted with $\mathrm{AD}$, studies have shown that curcumin potentially binds to $A \beta$ peptides, preventing aggregate formation of new amyloid deposits as well as promoting the de-aggregation of the existing amyloid deposits. Analogues of curcumin, namely desmethoxycurcumin and bis-desmethoxycurcumin, have also shown protective ability against $A \beta$-induced oxidative stress. Moreover, curcumin causes the inhibition of $A \beta$ oligomerization and formation of fibril, causes a macrophage enhancement of $A \beta$ uptake, and inhibits the A beta-heme complex peroxidase activity. Other components of turmeric such as curcuminoids and polyphenolic compounds attenuate mitochondrial dysfunction, inflammatory response induction, and oxidative stress in the presence of inflammatory cytokines such as iNOS and COX-2. Curcuminoids can also bind to A $\beta$ plaques, causing inhibition of amyloid accumulation and its aggregation in the brain [63].

\section{- Celastrus paniculatus Wild}

Celastrus paniculatus Wild, commonly called as Jyotishmati, belongs to the Celastraceae family. Traditionally, it was administered as a powerful appetite stimulant, brain tonic, and emetic. Phytochemical studies show the presence of a sesquiterpene, evoninoate, alkaloids paniculatine A and B, wifornine F celapagine, celapanine, celastrine, celapanigine, polyalcohols such as malkanginnol, paniculate diolmalangunin, and malkanguniol, triterpenoids, and sterols such as $\beta$-amyrin and $\beta$-sitosterol. Scientific studies suggested that Celastrus paniculatus water extract modulated the glutamate receptor function that protects neurons against toxicity produced by the glutamate and resulted in the improvement in memory and learning. It also causes a noteworthy decrease in the MDA level in the brain, which is an important marker of oxidative damage, with simultaneously significantly increases in levels of glutathione and CAT; two endogenous antioxidants in the brain [63]. Jakka et al. [66] investigated research that explained the neurotrophic potential in Celastrus paniculata Wild whole plant methanolic extract (CPPME). A significant decrease was also seen in AChE and enhanced neurotrophic activity, which ultimately improved spatial memory formation in scopolamine-induced amnesia.

\section{- Coriandrum sativum L}

Coriandrum sativum L., also referred to as dhanya, belongs to the family Apiaceae [30]. The major phytochemicals present include flavonoids such as quercetin 3-glucoronide, and polyphenolics such as protocatechinic acid, glycitin, and caffeic acid. In seeds, the flavonoid content was reported at a concentration of 12.6 quercetin equivalents $/ \mathrm{kg}$ and the polyphenolic concentration was reported at 12.2 gallic acid equivalents $/ \mathrm{kg}[67,68]$. A study reported that the Coriandrum sativum extract caused an increase in total protein concentration and enzyme levels of CAT, SOD, GSH, and reduced the size of cerebral infarct, calcium levels, and lipid peroxidation (LPO) in the experimental rat. Scopolamineand diazepam-induced memory deficits were also decreased by Coriandrum sativum leaves. The leaves also show an antioxidant property, having radical scavenging activity of DPPH with lipoxygenase inhibition and phospholipid peroxidation inhibition activity, which contribute to its memory enhancement effect [69].

\section{- $\quad$ Galanthus nivalis}

Galanthus nivalis, referred to commonly as snowdrop, belongs to the family Amaryllidaceae. Galantamine is the major constituent found in the bulbs and flowers of Galanthus nivalis and is a tertiary iso-quinoline alkaloid. The neuroprotective effect exerted by Galantamine is associated with a dual action. The drug is a competitive and selective AChE inhibitor and can stimulate nicotinic receptors, which further enhance cognition and memory [70].

\section{- Ginkgo biloba}

Gingko biloba belongs to the Ginkgoaceae family and is considered a 'living fossil'. Its extract majorly consists of flavonoids, whose fraction accounts to $24 \%$. It mainly comprises of flavanols such as, isorhamnetin, quercetin, kaempferol, and terpene lactones, which account to a concentration of $6 \%$ and further comprise diterpenic lactones such as ginkgolides $\mathrm{A}, \mathrm{B}$, 
C, J and M, and a sesquiterpene tri lactone-bilobalide. The extract exhibits neuroprotection by several mechanisms such as membrane lipid peroxidation inhibition, anti-inflammatory activity, as well as through direct inhibition of amyloid-b aggregation and anti-apoptotic activities. The flavonoid fraction of Ginkgo biloba (G. biloba) extract has a free-radical scavenging property as well as anti-oxidative effects, while bilobalide has been associated with a decrease in damage caused due to excitotoxicity and global brain ischemia-induced death of neuronal cells. Extract of G. biloba in the brain significantly inhibits the AChE activity, which indicates that the level of acetylcholine has increased considerably. Flavonoids alter several biological processes through interaction with signalling pathways, effects on protein neuronal expression, which is imperative for plasticity and repair of the synapse, variation in cerebral blood flow, and neuropathological inhibition of processes in certain cortical regions. A study by Dash SK presented that the G. biloba extract causes a decline in cortical A $\beta$ levels through a reduction in cholesterol levels as free and circulating cholesterols affect amyloid genesis [71].

- Glycyrrhiza glabra

Glycyrrhiza glabra, widely referred to as Yashti-madhuh or liquorice, belongs to the Leguminosae family. Its major constituent is a flavonoid called Glabridin, which possesses multiple pharmacological activities such as anticancer, antiviral, anti-ulcer antioxidant, antidiabetic, immunomodulatory activity, anti-inflammatory activity, antimicrobial activity, and anticonvulsant activity. Liquorice significantly increased learning and memory, however, research has indicated that its consumption improves general intelligence rather than short-term memory. In the brain, glabridin decreases the MDA level, and increases the superoxide dismutase level while reducing glutathione levels. A study suggested that G. glabra administration restored the decreased concentration of dopamine and glutamate in the brain and decreased activity of AChE [72].

\section{- Hypericum perforatum}

Hypericum perforatum is also known as millepertuis or hypericum. It belongs to the family Hypericaceae. Although it is found worldwide, it is mainly native to Europe, northern Africa, and western Asia. The main active component of H. perforatum is Hyperoside. Hypericin, kaempferol, biapigenin, and quercetin comprise the other constituents. The extract of H. perforatum has been reported to behave as a protector against NADPH-dependent (enzymatic) and $\mathrm{Fe}^{2+}$ and ascorbate-dependent (non-enzymatic) peroxidation of lipids in the cortical region of the brain. The extract also protects brain cells from cytotoxicity brought about by glutamate through the reduction of glutathione loss, overload of calcium, and cell death mediated through ROS. The ethanolic extract of $\mathrm{H}$. perforatum may also bring about an improvement of microglial viability through the reduction of toxicity by amyloid-beta in AD. Hypericum perforatum inhibits AChE and MDA formation in the brain and increases the concentration of SOD, GPx and CAT. Therefore, H. perforatum also has the capability to bind to iron ions, has scavenging activity for hydroxyl radicals, and behaves as an antioxidant [73].

\section{- Lycopodium serratum}

Lycopodium is also referred to as ground pines or creeping cedar. It belongs to the family Lycopodiaceae, which comprises a family of fern-allies. Its leaves contain a single, unbranched vascular strand and are microphylls. The major constituent is huperzine A, which is a potential therapeutic agent by researchers for treating AD. The alkaloid, which has been isolated from Lycopodium serratum, has been used for treating inflammation, fever, and blood disorders for many decades. It acts as a highly reversible, potent, and selective inhibitor of $\mathrm{AChE}$ and is comparable to the potency observed by galantamine, physostigmine, tacrine, and donepezil. Huperzine A is considered to be a strong candidate for therapy in AD. It has been found that huperzine A causes a noteworthy upregulation in AChE levels in rat brains and is associated with protective effects such as amyloid precursor protein metabolism regulation, oxidative stress protection mediated by $\mathrm{A} \beta$, apoptosis, dysfunction of mitochondria, and anti-inflammation [74]. 
- Melissa officinalis

Melissa officinalis L. (Lamiaceae) leaves are commonly referred to as lemon balm and have been used traditionally for spasmolytic and nerve calming effects. The leaves produce a calming and soothing effect through interaction with the $\mathrm{GABA}_{\mathrm{A}}$ benzodiazepine receptor. Its extracts contain flavonoids, namely quercitrin, apigenin, luteolin along with phenolic acids. The derivatives of these products inhibit enzymes such as monoamine oxidases (MAO) and AChE, which scavenge these free radicals and prevent apoptosis. Enzymatic inhibition of the above-mentioned enzymes leads to alleviation of depression symptoms. Research also suggests that Melissa officinalis produces protective effects in the PC12 cell line and protects neurons from oxidative stress [75].

- Ocimum sanctum

Ocimum sanctum is commonly referred to as 'Tulsi' in Hindi and in English, 'Holy Basil'. It belongs to the Labiatae family. The plant is reported to contain glycosides, alkaloids, saponins, tannins, vitamin C, citric acid, tartaric acid, and maleic acid. Research conducted by Kusindarta et al. [76] indicated that an ethanolic extract derived from the leaves of Ocimum sanctum may stimulate and restore choline acetyltransferase expression in human ageing cerebral microvascular endothelial cells and could provide nerve protection and increased production of Ach, which may enhance memory and cognitive ability. Scientific studies reveal that the hydro-alcoholic extract of Ocimum sanctum exhibits strong antioxidant activity against DPPH and hydroxyl radicals, which possibly occur due to the presence of a high number of polyphenols and flavonoids. It inhibits peroxidation of lipids, ROS generation, damage to DNA, and depolarization of membranes. It also decreases the enzymatic leakage of lactate dehydrogenase, preserves cellular morphology, restores superoxide dismutase, and catalyses enzyme levels, thereby preventing neuronal damage [77].

\section{- Panax Ginseng}

Ginseng belongs to the Araliaceae family and is prominently found in north-east Asia. It is used world-wide for boosting energy. Ginseng may provide neuroprotection against neuronal degradation through various mechanisms such as production of a reduction in the $\beta$-amyloid deposition or glutamate-induced excitotoxicity in a dose-dependent manner, thereby preventing apoptosis and neuronal death, improving routine in a passiveavoidance learning paradigm, and protecting neurons possibly through its potential to suppress cellular AChE activity and enhance cholinergic metabolism [78].

\section{- Rosmarinus officinalis}

Rosemary, commonly known as Satapatrika, belongs to the Lamiaceae family. It contains many essential oils such as eugenol, carvacrol, oleanolic acid, and ursolic acid, and thymol constituent's antioxidants such as ferulic acid and carnosic acid, which can be used against cyanide-induced damage in brain. A neuroprotective effect is also seen, which can be cultured and human-induced, as has been observed in rodents, cell-derived neurons, and pluripotent stem cells in vivo and in vitro in various parts of the brain in non-Swiss albino mouse models. It also possesses cytoprotective, anti-apoptotic, and anti-inflammatory activities that also add on to its neuroprotective mechanism [79].

\section{- Salvia officinalis}

Salvia officinalis belongs to the Lamiaceae family, and is well-known and reputed for improving memory, as it has been traditionally used as a memory enhancing agent. Carnosic acid and rosmarinic acid are the active ingredients found in S. officinalis. These components are known to have potential pharmacological activity such as antioxidant and anti-inflammatory properties as well as a low AChE inhibitory effect. It inhibits ROS formation, peroxidation of lipids, fragmentation of DNA, activation of caspase-3, and hyperphosphorylation of protein tau. Clinical evidence that has been obtained may help to prevent or reduce the symptoms of dementia. A small pilot trial involving the oral 
administration of S. officinalis essential oil to 11 patients that possessed mild-to-moderate symptoms of AD improved cognitive function significantly [80].

- Terminalia chebula

Terminalia chebula (T. chebula), also known as "King of Medicines" in Tibet, belongs to Combretaceae family. It has been widely used as traditional medicine in Ayurveda, Siddha, Unani, and Homeopathy. It contains compounds such as arjungenin, triterpene sarjunglucoside 1 , and the tannins, chebulosides 1 and 2, chebulic acid, chebulinic acid, tannic acid, ellagic acid, 2,4-chebulyi- $\beta$-D-glucopyranose, gallic acid, ethyl gallate, punicalaginterflavin $\mathrm{A}$, and terchebin. It also has presence of flavonoids such as rutins, luteolin, and quercetin. A study reported that T. chebula exhibits anxiolytic activity and is equivalent to standard drug diazepam. T. chebula has good pharmacological activities relevant to dementia therapy and possesses antioxidant activity comparable to radical scavengers such as quercetin, reflecting 95\% activity, and showing an inhibitory concentration (IC50) value of $2.2 \mu \mathrm{g} / \mathrm{mL}$. T. chebula fruit extract also shows protective effect neuronal cells against ischemia, reduces least production, and stimulates microglia cells death rate by lipopolysaccharide [81].

- Tinospora cordifolia

Tinospora cordifolia (T. cordifolia) belongs to the Menispermaceae family, which is commonly known as giloe. Chemical constituents extracted from the plant are alkaloids, diterpenoid lactones, steroids, glycosides, and aliphatic acids. T. cordifolia holds a memory increasing property, which is due to immune-stimulation and increased synthesis of acetylcholine. T. cordifolia exhibits the property of scavenging free radical activity against ROS and reactive species of nitrogen, which have been studied through electron paramagnetic resonance spectroscopy. It increases the concentration of glutathione and the expression of the gamma-glutamyl-cysteine ligase and superoxide dismutase of copper-zinc genes, which play a major role in neuronal injury during hypoxia and ischemia. In addition, T. cordifolia significantly decreases the mRNA expressions of iNOS. T. cordifolia also increases the dopamine level of the brain. Thus, T. cordifolia has shown to prevent neurodegenerative changes and enhance cognition, learning, and memory [82].

\section{- Withania somnifera}

Withania somnifera belongs to the family Solanaceae and is popularly known as Ashwagandha or Indian ginseng. The major constituents of Ashwagandha root are two withaferin A, withanolide D, and withanolides. Active glyco-withanolides of Withania somnifera have a significant antioxidant function, which is accomplished by elevating the activities of SOD, CAT, and GPx. It is also reported that Ashwagandha also works as a nerve tonic that boosts energy and rejuvenates the cells. According to Rajasankar et al. [83], treatment of PD mice with an oral dose of Withania somnifera root extract $(0.1 \mathrm{~g} / \mathrm{kg}$ body weight) for 1 week or 4 weeks enhanced homo-vanillic acid and dopamine, 3,4-dihydroxy phenyl acetic acid levels in the corpus striatum. Furthermore, the report suggested that Withania somnifera treatment enhances the anti-apoptotic proteins level such as Bcl-2 and depreciates the pro-apoptotic protein level such as Bax in the Maneb-Paraquat-induced dopaminergic neurodegeneration model of PD. Ashwagandha extract has shown to prevent lipid peroxidation and increase antioxidant activity by increasing the free-radical slinking enzymes levels in the brain [63].

\section{- Zizyphus Jujube}

Jujube fruits are used in Korean and Chinese traditional medicine to reduce anxiety and strengthen the stomach and gastrointestinal system. Jujube seeds comprise large amounts of flavonoid, phenyl glycosides, terpenoid, and alkaloid compounds mucilage, citric acid, malic acid, sugar, organic minerals, vitamin $C$, and protein. The herb exerts inhibition activity against the release of histamine, cyclooxygenase I and II, and AChE inhibitory activity. Flavonoids present antioxidant properties [63]. A compound known as cis-9octadecenamide (oleamide) extracted from jujube is reported to bring about an upregulation of acetylcholine transferase to $34.1 \%$ in the in vitro models, which leads to the increase in 
acetylcholine level and improves mild-to-moderate cognitive functions, motor coordination, behavioural disorders, learning, and memory [84].

\subsection{Conventional Approach}

As a harsh reality in ND and As, the only hope is symptomatic treatment. The symptomatic treatment therapies rely on slowing down symptoms without addressing the cause and cure of the disease. Apart from symptomatic treatment, the other strategy that is being employed currently is disease modifying-based treatment. Inhibitors of anti-cholinesterase are used as symptomatic treatment, while anti-inflammatory agents and antioxidants are used for disease modifying treatment [85]. Current therapies for neurodegenerative and neurological disorders usually are involved in managing symptoms instead of providing significant activity against disease progression. For example, the symptoms of HD are controlled using $75-200 \mathrm{mg} /$ day of tetrabenazine to alleviate involuntary movement (chorea). However, as it acts as a vesicular monoamine transporter inhibitor (VMAT), it causes an interference with both 5-HT (5-hydroxytryptamine) and dopamine (DA) degradation, and, as a result, patients can show neuropsychiatric-based symptoms along with various other side effects [86]. Various other first-line treatments such as L-Dopa in PD often cause a multitude of side effects and do not delay progression of the disease. Another example is that of cholinesterase inhibitors such as Donepezil, which is minimally effective in providing improvement in cognition required for $\mathrm{AD}$ treatment. The various conventional strategies used currently in the treatment of the two most common NDs, AD and PD, are summarized in detail in Table 1 [87].

In view of the above information, there is an essential requirement for the development of novel therapeutics that possess lesser or tolerable side effects to overcome these disease states, which can further improve the quality of life of the ageing population. Conventional drug delivery strategies, in general, fail to cross the BBB and are therefore less efficacious in terms of treatment [88]. 
Table 1. Summary of the various conventional strategies used for the treatment of AD and PD.

Strategy

Alzheimer's Disease

Parkinson Disease

Modulation of neurotransmitters (approved therapies)

Disease modifying therapies (under investigation)

Immunotherapy

\section{Amyloid based therapy}

- $\quad$ Secretase modulation

- Amyloid aggregate prevention

- Amyloid clearance promotor

2. Tau-based therapy

- Tau hyperphosphorylation inhibition

- Tau protein degradation

- Tau oligomerization inhibition
- $\quad$ Precursors of Dopamine

- MAO-B inhibitors

- COMT inhibitors

- Dopaminergic agonists

- Anti-cholinergic
- Passive immunization

Solanezumab

Crenezumab

- $\quad$ Active immunization CAD106
1. $\alpha$-Synuclein-based therapy

- Amyloid aggregate prevention

- $\alpha$-synuclein fibril formation blockade

- Modulation of $\alpha$-synuclein related lipidome

2. Non-dopaminergic therapy

- Antagonists of adenosine receptor

- Antagonists of NMDA

- $\quad$ Agonists of Glucagon such as peptide-1

Gene-based therapy Regulation of presenilin expression

Other

- ROS reduction, oxidative stress reduction

- Anti-inflammatory agents

- Caspase inhibitors

- Metal chelators, Statins

- PPAR- $\gamma$ (Peroxisome proliferator-activated receptor- $\gamma$ )
- $\quad$ Passive immunization Solanezumab

- $\quad$ Active immunization PD01A 


\section{Recent Trends of Phyto-Neuro Medicine}

The latest advancements in the domains of green chemistry and nanotechnology are promising and indicate significant potential in the advancement of biomedical sciences from a theranostic perspective $[89,90]$. However, this potential, so far, has not been utilized for the development of therapeutics for NDs such as AD and PD. The utilization of chemically synthesized molecules poses limitations such as toxicity and cost [89,91,92]. In addition, a study reported that some chemicals that are used for the chemical synthesis of NPs have the propensity to remain attached on the NP surface and as a result, could not be applied biomedically. Therefore, focus has moved towards the development of materials using green chemistry and a green process [93]. Traditionally, the utilization of the green chemistry-based approach is based on the use of medicinal plants or phytochemicals in their pure form that possess medicinal properties, as these phytochemicals provide chelation and stability to the NPs [90].

Recently, Suganthy et al. [94] reported the neuroprotection offered by biogenic gold NPs based on Terminalia arjuna. The results obtained showed significant biocompatibility of biogenic gold NPs as well as significant neuroprotection. These particles successfully inhibited the $\mathrm{AChE}$, caused a reduction in the $\mathrm{A} \beta$ fibrillation process, and at low concentrations caused a destabilization of mature fibrils. Trehalose functionalization of synthesized gold NPs brought about a significant improvement in the inhibition of protein aggregation along with the disintegration of mature fibrils, and possesses the potential for application in photothermal therapeutics [56]. Functionalization of gold NPs with anti-amyloidogenic molecules can be considered as a promising strategy for ensuring improvement in the neuroprotective nature. Another strategy involves the use of biogenic platinum NPs biosynthesized through utilization of Bacopa monnieri as a neuroprotective agent. Functionalization of NPs using phytochemicals has yielded significant results. Recently, functionalization of selenium NPs using polyphenols was achieved, where in nanoscale selenium nanoparticles were coated with EGCG, which is a polyphenol present in tea. EGCG does possess neuroprotective effects as well as inhibitory actions against a multitude of proteins that are amyloid-forming such as amyloid beta, transthyretin, $\alpha$-synuclein, and huntingtin, which are involved in AD disease progression. These particles were further coated with Tet-1, which is a protein that has strong affinity to neurons. The use of curcumin and its derivatives in a similar manner has led to therapies that show promising results in patients with AD. Benzothiazolinone in conjugation with curcumin has a strong binding affinity to amyloid and therefore can be used for targeted delivery of curcumin or various other natural products that can help in the treatment of AD [95].

Because of its significant antioxidant and anti-inflammatory effects, Yusuf et al. created PLGA NPs loaded with thymoquinone (TQ) to operate on this aspect in animal models [96]. Streptozotocin (SZT)-treated male albino mice were treated with TQ-loaded PLGA NPs coated with polysorbate 80, which mimics AD oxidative stress by decreasing Streptozotocin (SOD) activity (P-80-TQN). With an average particle size of $226 \mathrm{~nm}$ and a zweta-potential of $45.6 \mathrm{mV}$, the single-emulsion solvent evaporation technique was used to create these nanoparticles. Initial bursts of TQ release were seen after $2 \mathrm{~h}$, followed by a prolonged sustained release (stabilised dipole-dipole interactions taking place between TQ and PLGA components). Endocytosis via LDL receptors allowed the P-80-TQ NPs to traverse the BBB (mediated by the polysorbate coating). These systems had a considerable impact on SOD activity (increase) from the seventh to the 28th day after arrival on site. Further proving their positive impact, a study on animals and cognition (the "Despair test") was conducted at the same time.

Uncaria species have yielded the spirocyclic alkaloid rhynchophylline (RIN), which has been shown to have a variety of pharmacological effects, including neuroprotection. RIN suppresses soluble A-induced hyperexcitability of hippocampus neurons in the event of Alzheimer's disease. In 2020, Xu et al. released the first research on the design and development of brain-targeting treatment for Alzheimer's disease via RIN injection [97]. 
Methoxy Polyethylene Glycol NPs coated with Tween 80 were synthesised using the nanoprecipitation process to improve RIN's pharmacological activity and target specificity. T80-coated RIN-loaded PLGA NPs showed no haemolysis, indicating that these NP solutions might be safely used. In confocal laser scanning microscopy, internalisation into bEnd. 3 cells was demonstrated using DiD fluorophore-loaded PLGA NPs; T80-coated NPs showed more penetration. An in vitro BBB model using bEnd.3 cells was constructed to evaluate the crossing of such nano-systems and indicated their greater transport relative to free RIN or uncoated RIN laden NPs. Utilizing healthy C57BL/ 6 mice, the advantages of using T80 to target the brain were subsequently shown. Ultimately, incubation with T80 RIN NPs increased the survival rate of PC12 cells damaged by A25-35 while also reducing cell death. RIN neuroprotective effects were unaffected by the encapsulation of PLGA nanoparticles, as shown by these findings.

In totality, phyto-nanomedicines are promising as compared to currently marketed therapies for neurodegenerative disorders. Phytochemical derived nanomedicine could prospectively in future be used for neurodegenerative disorders due to their multitude of properties such as anti-inflammatory, antioxidative, and anticholinesterase activities. Further research, however, is necessary to investigate the complete neuroprotective ability of these compounds, to understand the mechanisms by which they exert protective effects, as well as determining whether combination therapy could be synergistic as neuroprotectants [85].

Undoubtedly, phyto-nanomedicines offer a great hope in developing treatment strategies against ND because of their fewer side effects and better target specificity. However, there are still a few limitations which must be considered. A limitation of the utilization of making use of the nanotheranostics for the treatment of NDs was identified by Kumar et al. in 2020. They found that due to variations in neural functioning, characteristics, and genome, a particular single approach cannot be used for all patients for the treatment of a particular disease. Another study by Kumar et al. [88] showed that this technique was proving to be ineffective as the NPs absorption time used in the technique was very low and if the injection is not performed adequately, there is a possibility of NP absorption in the blood or other body parts instead of the targeted area. Another constraint that was identified was that the treatment cannot be monitored in an effective and efficient manner, which poses a major challenge for the practitioners as they would be unable to track the progress and impacts of the treatment. In addition, the treatment and technique, besides being unproductive, is also extremely costly [88].

\subsection{Protein-Based Nanoparticles}

Because of their low toxicity and biodegradability, biopolymer-based nanoparticles, such as protein nanoparticles, have recently been actively employed as medicinal and functional tools [98]. Proteins are versatile building blocks for nanoparticles because of their specific roles in biology and the industrial industry. Endocytic transport of protein nanoparticles is possible because of their tiny size. As a drug delivery strategy, protein nanoparticles offer a number of benefits, including biodegradability, stability, surface modification, simplicity of particle size control, and less concerns related with toxicity issues, such as immunogenicity. Protecting the medication against enzymatic breakdown and renal clearance may increase its stability, activity, and half-life in particular. Additionally, protein nanoparticles may be employed in a number of targeted therapeutics, including cancer therapy, tumour treatment, and vaccinations, because of their non-antigenic properties. When protein nanoparticles are embedded in biodegradable polymers, they may be released over a long period of time. It is the primary goal of nanoparticle design to manage particle size and surface area so that nanoparticles containing the requisite quantity of pharmaceuticals may demonstrate desirable pharmacological activity by discharging active substances to produce part-specific action.

In silk fibres, the fibroin protein accounts for between 65 and 85 percent of the total protein content [99]. Degumming with $\mathrm{Na}_{2} \mathrm{CO}_{3}$ removes exterior sericin from silk produced by the Bombyx mori silkworm, a technique often used to extract fibroin [100]. As a result 
of its excellent mechanical strength, flexibility, low immunogenicity, biodegradability, and biocompatibility, fibroin has become a popular choice for the creation of nanoparticles. Fibroin nanoparticles' zeta potential is negatively charged. When a positively charged polymer such as PEI or chitosan is applied to the surface, it serves as a crosslinking agent that transforms the surface into a positive charge. The average size, size distribution, surface zeta potential, drug encapsulation, release profile, and particle formation stability of FNP may be affected by a variety of parameters, including fibroin molecular weight (MW), crystallinity, encapsulated drug characteristics, and production circumstances. Much research has been undertaken to distribute and use fibroin nanoparticles as a medication delivery method because they can overcome the drawbacks of low-molecular-weight medicines. Drug solubility and stability are enhanced, drug degradation is inhibited, and toxicity is reduced in all fibroin nanoparticles loaded with small molecule pharmaceuticals, making them better for drug therapy.

Approximately 585 amino acids make up HSA, which has a molecular weight of $66 \mathrm{kDa}$ [101]. HSA is mostly present in the bloodstream. Subunits A and B may be found in each of the three major components of the HSA. Sudlow's sites I and II, found in subunits IIA and IIIA of the HSA, are the primary binding sites [102]. When HSA is used as a carrier for other compounds, it helps hydrophobic molecules become more easily soluble in blood. A variety of chemicals may be delivered to particular tissues in the body via HSA. The $\mathrm{pH}$ (stabilised in the $\mathrm{pH}$ range of 4 to 9) and temperature (may be heated at $60^{\circ} \mathrm{C}$ for up to $10 \mathrm{~h}$ ) of HSA are also highly stable, as they are organic solvents [103]. Because of its biodegradability, non-toxicity, and non-immunogenicity, as well as its high solubility, it has the added benefit of being derived from biological sources. In investigations on protein binding and targeted medication administration, bovine and HSAs are often used because of these benefits. Due to HSA's strong affinity for diverse medications, a matrix of HSA nanoparticles may efficiently incorporate these molecules.

Table 2 describes the outcomes obtained following administration of drug-entrapped NPs for neurological disorders. 
Table 2. Summary of the materials used, active moiety entrapped, and outcomes obtained upon administration of NPs.

\begin{tabular}{|c|c|c|c|c|}
\hline Material & Name of Active Moiety Entrapped & Size & Outcome of Study & Reference \\
\hline Cholesterol & $\alpha$-bisabolol & $139.5 \mathrm{~nm}$ & $\begin{array}{l}\text { NPs drastically decrease free radical generation, lower } \beta \text {-secretase, } \\
\text { caspase-3, cholinesterase, and Bax expression, and increase Bcl-2 } \\
\text { protein expression. }\end{array}$ & [104] \\
\hline Cetyl palmitate miglyol-812 & Quercetin & $200 \mathrm{~nm}$ & $\begin{array}{l}\text { It is non-toxic to hCMEC/D3 cells and penetrates the BBB more so } \\
\text { than free drug. NPs also prevent A peptide fibril production. }\end{array}$ & [105] \\
\hline $\begin{array}{l}\text { Caprylic and capric triglycerides, } \\
\text { sorbitan monostearate }\end{array}$ & Curcumin & $247 \mathrm{~nm}$ & $\begin{array}{l}\text { Curcumin-NPs protect against A42-induced behavioural and } \\
\text { neurochemical alterations in AD mice model. }\end{array}$ & [106] \\
\hline PLGA & Curcumin & 150-200 nm & $\begin{array}{l}\text { Curcumin encapsulated-PLGA nanoparticles, destroyed amyloid } \\
\text { aggregates, exhibited an anti-oxidative property, and } \\
\text { are non-cytotoxic. }\end{array}$ & [107] \\
\hline DSPE-PEG2000-MAL & Quercetin & $200 \mathrm{~nm}$ & $\begin{array}{c}\text { After } 4 \text { h, RVG29-nanoparticles had } 1.5 \text { times the permeability across } \\
\text { the blood-brain barrier compared to } \\
\text { non-functionalized nanoparticles. }\end{array}$ & [108] \\
\hline PEG, PLGA & Epigallocatechin-3-gallate & $100 \mathrm{~nm}$ & $\begin{array}{l}\text { GCG and AA NPs resulted in a marked increase in synapses, as } \\
\text { judged by synaptophysin (SYP) expression, and reduction of } \\
\text { neuroinflammation as well as amyloid } \beta(\mathrm{A} \beta) \text { plaque burden and } \\
\text { cortical levels of soluble and insoluble } A \beta(1-42) \text { peptide. }\end{array}$ & [109] \\
\hline $\begin{array}{c}\text { poly(ethylene } \\
\text { glycol)-co-poly( } \varepsilon \text {-caprolactone })\end{array}$ & Ginkgolide B & $91 \mathrm{~nm}$ & $\begin{array}{l}\text { NPs facilitated the sustained release of GB into the blood, thereby } \\
\text { improving its ability to accumulate in the brain and to treat PD. }\end{array}$ & [110] \\
\hline $\begin{array}{l}\text { chitosan poly } \\
\text { ethyleneglycol-poly lactic acid }\end{array}$ & Acteoside & $100 \mathrm{~nm}$ & $\begin{array}{c}\text { Significantly reversed dopaminergic (DA) neuron loss in the } \\
\text { substantia nigra and striatum of sick mice. }\end{array}$ & [111] \\
\hline $\begin{array}{l}\text { Monomethoxy polyethylene } \\
\text { glycol }\end{array}$ & Apomorphine (AMP) & $100 \mathrm{~nm}$ & $\begin{array}{c}\text { The encapsulation of AMP into the nanoparticles inhibits oxidization. } \\
\text { The intranasal administration of the AMP-loaded nanoparticles } \\
\text { transports AMP across the BBB. }\end{array}$ & [112] \\
\hline
\end{tabular}




\subsection{Polymeric Nanoparticles}

Polymeric nanoparticles are colloidal particles that have a medication encapsulated inside a biodegradable and biocompatible polymer carrier, ranging in size from 1 to $1000 \mathrm{~nm}[100,113]$. Polylactide, polylactide polyglycolide copolymers, and polyacrylates are some of the most widely used polymers. Among them, Lactide glycolide copolymer has been widely studied. There are several natural polymers to choose from, including alginate, albumin, and chitosan. Various research has been ongoing for many years to establish the efficacy of curcumin (Indian solid gold) in a variety of disorders, including cancer. It was shown that curcumin was able to reduce Amyloid beta deposition and tau phosphorylation in an animal study on AD.

In addition, it increases the multiplication of neural stem cells and hippocampus neurogenesis [114]. As Curcumin has a weak water solubility, the nanoparticle format of Curcumin is thought to boost its ability to target neurons in Alzheimer's disease (AD). Curcumin nanoparticles Tet-1-targeted PLGA-coated curcumin were tested for the treatment of Alzheimer's disease by suppressing amyloid and antioxidant activities [107]. Nanoparticles having a zeta potential of 230 to $220 \mathrm{mV}$ and an average size of 150-200 nm were manufactured using the solvent evaporation technique. These nanoparticles are entirely soluble in water, and they also have the ability to glow. Studies on the viability of cells have shown that these nanoparticles are not harmful to cells. According to fluorescence data, the uptake of nanoparticles targeted with Tet-1 peptide in GI-1 glioma cells in an in vitro uptake assay was significantly increased compared to the non-targeted nanoparticles.

\subsubsection{Liposomes-Based Drug Delivery Systems}

Liposome transport mechanisms across the blood-brain barrier are still at the budding stage. Electrostatic interactions are the method by which the negative charges on BBB and cationic liposomal drug delivery systems induce cell internalisation through absorption mechanism [115]. It is possible to traverse the BBB by attaching glucose and GSH to liposomes as nutrients. Because of the therapeutic potential of receptor-mediated transcytosis, which has the ability to connect specific ligands to a wide variety of BBB receptors [116]. Using nanoliposomes that have been double-functionalized with curcumin and HIV TAT peptide, A peptide affinity is increased and BBB bridging is improved [117]. Endocytosis and micropinocytosis were the two most often cited mechanisms for TAT uptake. A thiolmaleimide reaction covalently links TAT to nanoliposomes. TAT-CurcNL has a size range of 196.5 to $3.2 \mathrm{~nm}$ and was quantified using HPLC-MS/MS. Mass spectrometry, confocal microscopy, and a radioactivity assay using [3H]-sphingomyelin [42] all showed a threefold increase in nanoliposome absorption after TAT functionalization in human brain capillary endothelial cells (hCMEC and D3).

Mourtias also used the thin film hydration approach to make multifunctional nanoliposomes containing curcumin-lipid derivatives. When DSPE-PEG2000 was reacted with 4-methoxytrityl-thiol for the first time, it produced DSPEPEG2000-S-Mmt, which is the precursor to DSPE-PEG2000SH, a functionalized lipid available on the market. There were no by-products and the reaction proceeded quickly in the presence of DIPEA (Diisopropylethylamine) during the DSPE-PEG2000-S-Mmt synthesis [118]. A PEG spacer was added between curcumin and lipids to manufacture this derivative. When DSPEPEG2000-SH was deprotected with thiol, it reacted with curcumin to produce the DPSPEG2000-CURC derivative. Nanoliposome membranes were successfully included with this novel synthetic substance. For the second phenol-protons of the curcumin moiety, DIPEA was added and the resulting DIPEA salt was proved to effectively identify A deposits in post-mortem tissues of Alzheimer's disease (AD) patients' tissues. One of the best-selling herbal remedies, ginkgo biloba, has its origins in traditional Chinese medicine. Antioxidant activity in the CNS is observed to boost the activities of superoxide dismutase, catalase, glutathione peroxidase, and glutathione reductase. As a result of increased antioxidant activity in the hippocampi, Ginkgo biloba aids in memory and learning [119]. Non-ionic bilayer vesicles based on surfactants constitute niosomes. Unlike liposomes, niosomes may contain both 
hydrophilic and hydrophobic drugs in the same system $[47,120]$. It is possible that the niosomes containing medications for the treatment of CNS disorders may pass the BBB. In freeze-dried powder $(661 \mathrm{~nm})$ and spray-dried powder $(680 \mathrm{~nm})$, the size of niosomes is affected by the drying procedure. Spray-dried niosomes had a higher zeta potential than freeze-dried niosomes, on the other hand. Because the zeta potential of spray dried noisome powder is high, they are more stable, owing to the substantial electrostatic repulsion between particles [48,121].

\subsubsection{Green Synthesized Nanoparticles}

Green chemistry - in fact, green technology — is currently being pushed for its use in nanotechnology as an eco-friendly option. However, for herbal extracts, metal nanoparticles have been shown to be more favourable than microorganisms in the creation of nanoparticles. The organic components may decompose into biodegradable material because of the presence of polyphenols. Shankhapushpi is $\mathrm{n}$ antihypertensive, immunomodulatory, and anticonvulsant ayurvedic plant. The antioxidant capability of the ayurvedic medicine Convolvulus pluricaulis was discovered to improve memory in nanoparticles made using iron oxide as a precursor. Researchers are still trying to understand the molecular process of these micro particles [122]. As an anti-epileptic, insect repellent, and antioxidant, the Pulicaria undulata plant is also often used in traditional Chinese medicine. The increased concentration of silver nanoparticles (AgNPs) in the brain leads to an increase in AgNPs' interaction with proteins, which prevents fibril formation by decreasing protein conformation and self-association in Pulicaria undulata nanoparticles made with silver (AgNPs) [123].

\section{Nanotechnology-Induced Bioinformatics for Early Diagnosis}

In the last three decades, several computational programs have been continuously developed and applied to improve the quality of biomedicine in an interdisciplinary model. At the same time, the term bioinformatics, a combination of computational biology and mathematical algorithms, has been used for leading current biomedicine and biomedical research. Biological data-restoration (proteomics and genomics related to disease biology), biological data and text mining (analyses of massive amounts of data and text to restore biological data), and genomic-proteomic investigation (in the contest of mutation and drug resistance pathways and biomarkers) have been used to guide and solve several complex problems in biomedical areas through the wide range of cost and resource-saving technology. For example, the Human Genome Project and other OMICS (genomics, proteomics, metabolomics, and glycomics) projects have revolutionized bioinformatics support to biomedical research. Overall, integrated bioinformatics tools can gather and analyse massive amounts of biological and laboratory data to help understand diseases and select ideal therapies [124,125].

Simultaneously, nanotechnology is another demanding sector in biomedicine for generating more prospective technological and technical discoveries in medication delivery. Strategically, when nanotechnology is merged with bioinformatics, the phrase used is 'nano informatics', and this discipline has more potential for attaining breakthrough analyses in biomedical drug development applications [126,127]. Figure 2 illustrates the role of nano informatics for the development of therapies for dementia. Currently, nano informatics have become an emerging field and have been accepted by health and regulatory bodies such as US NSF, NIH, the National Cancer Institute, and the European Commission, etc., for analysing and processing the structure and physiochemical characteristics of nanoparticles, their formulation, as well as for their application in the treatment of various diseases such as neurodegenerative disorders and cancer. The experimentation for NDs is more expensive and sensitive. Bioinformatics can be used for early detection, understanding the disease, and application, while nanotechnology can be used for studying the diagnosis or treatment strategy through the use of drug delivery that is target specific $[125,127]$. 


\section{CURRENT APPLICATIONS OF BIOMEDICAL NANOTECHNOLOGY}

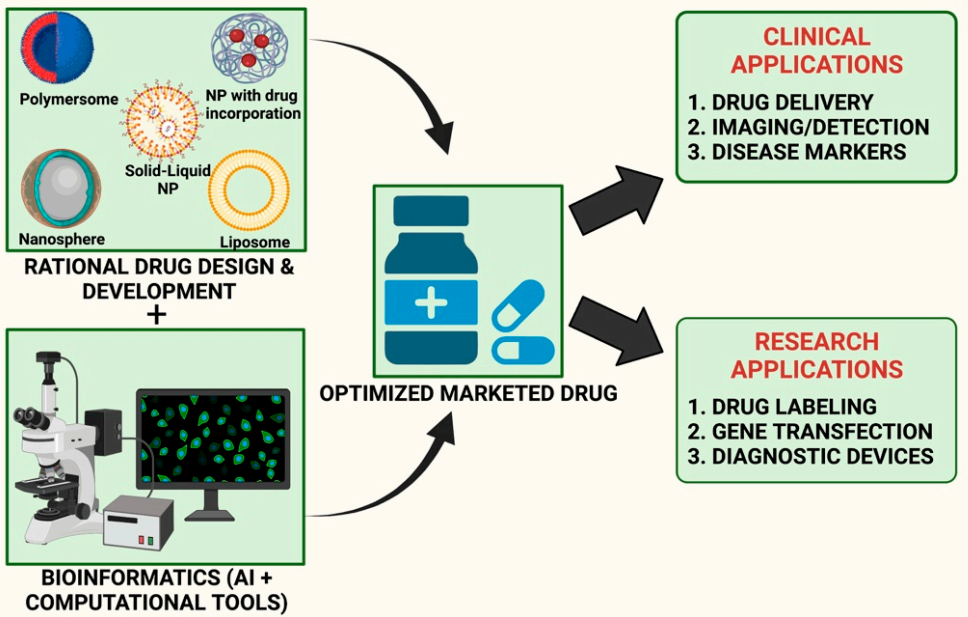

Figure 2. A schematic presentation of nano-informatic (nanotechnology and bioinformatics) in present dementia or neuro-disorder research.

Dementia, a brain disorder which is characterized by memory loss, is a common disorder; $\mathrm{AD}$ is its most predominant form, accounting to $60-70 \%$ of dementia cases, and about 10 million cases have been recorded per year. Mostly, in brain disorders, the synaptic transmission is affected, and its target is the ionotropic glutamate receptor (iGluR), which belongs to the most poorly understood pharmacological target, the G-coupled receptor (GPCR). However, the current updated research involves analysing brain physiology and targeting amyloid plaques amyloid-beta neurofibrillary tangles, tau protein, astrocyte associated $\beta$-secretase, cholinergic neuron associated butyrylcholinesterase, cognitive function in medial temporal lobe cortex, secretase (presenilin I), central nerves system associated GPCR-target, and dopamine-2 receptor, etc., for Alzheimer and dementia treatment $[128,129]$. In drug development, there are more than a hundred pipeline drugs under clinical investigation [130,131].

In the history of drug discovery, most drugs have failed due to lack of consideration of pharmacokinetics. These drugs are unable to cross the blood-brain barrier (BBB) [132,133]. For a drug to be active and to show the desired effect, the drug should have the ability to penetrate the BBB. Most of these drugs, however, have been unable to cross and as a result show about $<1 \%$ effectiveness as compared to the administered dose, or sometimes exert neurotoxicity. Therefore, the development of target-specific nano-drug delivery, which can pass through the BBB, can play an important role in the management and treatment of dementia or Alzheimer's diseases $[134,135]$. Nevertheless, so far, the nano system is insufficient, and attempts are ongoing for the optimization of nano systems and drug applications in NDs $[125,136]$. Through the use of nano informatic tools, the interaction-cum-efficacy of proposed therapeutic agents with the target protein can be predicted along with obtaining relevant information on the BBB profile and possible neurotoxicity side effects that can be observed. [54,137-140]. For example, tools namely, admetSAR (http://lmmd.ecust.edu.cn/admetsar2/) (accessed on 10 November 2021), SwissADME (http:/ / www.swissadme.ch/) (accessed on 10 November 2021), LightBBB (http://bioanalysis.cau.ac.kr:7030/) (accessed on 10 November 2021), as well as databases such as VariCarta (https://varicarta.msl.ubc.ca/index) (accessed on 10 November 2021), AlzGene (http:/ /www.alzgene.org/) (accessed on 10 November 2021), and NDDVD (http:/ /bioinf.suda.edu.cn/NDDvarbase/LOVDv.3.0) (accessed on 10 November 2021) have been used to obtain large data sets of neurological therapeutics. Overall, nano informatics could be a commanding approach towards exploring and understanding mechanisms along with locating and developing better suited and more efficacious therapeutic agents in a cost-effective manner. Table 3 summarizes the miRNAs used for treatment of neurological disorders. 
Table 3. List of miRNAs used as therapeutics (conventional and nonconventional) for some NDDs. The investigated drug, the miRNAs, their sources, the disease state as well as the references are indicated.

\begin{tabular}{|c|c|c|c|c|}
\hline Drug & miRNA & Source of miRNA & Disease State Used & Reference \\
\hline Donepezil & miRNA-206-3p & Mouse-Hippocampus, cortex & \multirow[b]{2}{*}{ Dementia } & [141] \\
\hline Simvastatin & miRNA-106b & $\begin{array}{c}\text { SH-SY5Y cells; Mice brain } \\
\text { tissue-APP/PS1 }\end{array}$ & & [142] \\
\hline \multirow{3}{*}{ Osthole } & miRNA-9 & overexpressed APP cells & \multirow{4}{*}{$\begin{array}{l}\text { Alzheimer's Disease } \\
\text { (AD) }\end{array}$} & {$[143,144]$} \\
\hline & miRNA-107 & Overexpressed APP cells & & [143] \\
\hline & miRNA-101a-3p & Mice brain tissue-APP/PS1 & & [143] \\
\hline AGR-GRg1 & miRNA-873-5p & Mouse Hippocampus & & [145] \\
\hline \multirow{4}{*}{ L-Dopa } & $\begin{array}{l}\text { miRNA-30b-5p, } \\
\text { miRNA-30a-5p }\end{array}$ & Plasma & \multirow{5}{*}{ PD } & [146] \\
\hline & $\begin{array}{l}\text { miRNA-29a-3p, } \\
\text { miRNA-30b-5p, } \\
\text { miRNA-103a-3p }\end{array}$ & $\begin{array}{l}\text { Peripheral Blood mononuclear } \\
\text { cells (PBMC's) }\end{array}$ & & [147] \\
\hline & $\begin{array}{l}\text { miRNA-16-2-3p, } \\
\text { miRNA-26a-2-3p, } \\
\text { miRNA-30a }\end{array}$ & Peripheral blood & & [148] \\
\hline & miRNA-155 & PBMCs & & [149] \\
\hline L-Dopa, Amantadine & $\begin{array}{l}\text { miRNA-7, } \\
\text { miRNA-9-3p, } \\
\text { miRNA-9-5p }\end{array}$ & Peripheral blood & & [150] \\
\hline \multirow{6}{*}{ Interferon- $\beta$} & miRNA-29 & PBMCs & \multirow{14}{*}{ Multiple Sclerosis } & [151] \\
\hline & miRNA-145 & Whole blood & & [152] \\
\hline & miRNA-29b-3p & \multirow{4}{*}{ PBMCs } & & [153] \\
\hline & miRNA-326 & & & [154] \\
\hline & miRNA-26a-5p & & & [155] \\
\hline & miRNA-146a & & & [156] \\
\hline \multirow{5}{*}{ Natalizumab } & miRNA-150 CSF, & Plasma & & [157] \\
\hline & $\begin{array}{l}\text { miRNA-126, } \\
\text { miRNA-17 }\end{array}$ & CD4 + T cells & & {$[158,159]$} \\
\hline & $\begin{array}{l}\text { miRNA-17 92, } \\
\text { miRNA-106b 25 }\end{array}$ & B lymphocytes & & [160] \\
\hline & $\begin{array}{l}\text { miRNA-26a, } \\
\text { miRNA-155 }\end{array}$ & PBMCs & & [153] \\
\hline & miRNA-155 & Monocytes & & [161] \\
\hline Dimethyl fumarate & miRNA-155 & Monocytes & & [162] \\
\hline \multirow[t]{2}{*}{ Fingolimod } & miRNA-150 & Plasma & & [163] \\
\hline & miRNA-23a & Whole Blood & & [164] \\
\hline Natalizumab & $\begin{array}{l}\text { miRNA-320, } \\
\text { miRNA-320b, } \\
\text { miRNA-629 }\end{array}$ & Blood & $\begin{array}{l}\text { Progressive multifocal } \\
\text { leukoencephalopathy }\end{array}$ & [163] \\
\hline
\end{tabular}

\section{Limitations of Nanotechnology-Based Approaches for ND}

Using nanotheranostic techniques to treat neurodegenerative illnesses, as discovered by Indrasekara et al. [165], have their limits because each patient has a unique genome and neurological functioning and features, and so no one strategy can be employed to treat all of them. Every person must be diagnosed and treated for these neurodegenerative conditions 
individually, which is a difficult undertaking and does not aid in establishing one approach or treatment methodology that works for everyone [166]. (De Lau et al., 2006).

In addition, Kim et al. found that if the injection is not performed properly, the NPs utilised in this approach may be absorbed by the blood or other body parts instead of the intended target location [167]. This is a difficulty or restriction that has been highlighted by Kim et al. If the medicine is not injected properly, it will not be absorbed or utilised to treat the intended location for treating neurodegenerative illnesses such as Alzheimer's disease and Parkinson's disease. Because just a little amount of the medication actually makes its way to where it is needed, some have contended that it has not yet been shown that the therapy is $100 \%$ successful [168].

In order to progress this study into viable therapeutic medicines, it is critical that safety concerns be addressed. As a reminder, the most successful NP formulations for the brain delivery nonetheless accumulate extensively in other parts of the body, such as the spleen, the liver, and the kidney. As a result, it is critical to create nanoformulations that are only activated when they reach the brain [169] instead of activating when they reach other parts of the body. Nanoparticles in regenerative medicine may soon benefit from advances in triggerable nanoformulation technology. The production of nanoparticles that target particular brain cells is a significant problem that warrants more study. Targeting particular brain cells such as dopaminergic neurons (the primary target in Parkinson's disease), microglia (neuroinflammation), or neural stem cells (neuronal repair) may boost its potential therapeutic usefulness in the context of neurodegenerative illnesses.

Multifunctionality is required for brain-targeting NP because of the BBB's protective role, which makes it challenging to target molecules to the brain parenchyma. As a matter of fact, the BBB's primary job is to protect brain tissue from potentially hazardous chemicals. NPs neurotoxicity must be examined for the same reasons as a more traditional medicinal system's neurotoxicity. Microglial activation is a critical consideration in NP neurotoxicity because it plays a role in the neurodegenerative pathogenic process in the vast majority of CNS illnesses. When using cultured microglial cells, an in vitro study found that $\mathrm{TiO}_{2} \mathrm{NPs}$ and HAP (hydroxyapatite) NPs were able to trigger inflammation-related iNOS (inducible nitric oxide synthase) and activate the NF-B signalling pathway. All the tested NPs induced, to a variable extent, the increase in pro-inflammatory molecules [170]. It was evidenced that $\mathrm{TiO}_{2}$ and HAP NPs may activate microglial cells and lead to probable pathogenic alterations in the olfactory bulb, striatum, and hippocampal regions of mice, concluding that these inorganic NPs contributed to the dysfunction and cytotoxicity in PC12 cells.

\section{Future Nano Therapeutics for ND}

Without a doubt, precision-based nanomedicine will gain more attention in the coming years. However, despite advances, the use of phages in humans has yet to gain widespread acceptance. There is a gap that must be bridged between animal trials and human use. Approval from the Food and Drug Administration is required, and it is likely to follow on the heels of increasingly promising research on phage-based nanomedicine [171].

Exosomes, which are naturally produced by human cells, are emerging as a new generation of highly protective nanoplatforms for efficient drug delivery [172]. They can transport not only therapeutics but also molecular imaging agents for use in precision therapeutics and diagnostics. Exosomes are an ideal nanoplatform for loading both hydrophilic and lipophilic agents due to their unique structure, which includes an aqueous core and a membrane rich in lipid rafts.

Nonetheless, despite the current promising research on exosomes, several major challenges remain to be overcome, including a lack of characterization of exosomes derived from different sources, low exosomal yield, and encapsulation efficiency, and a lack of advanced purification techniques with high efficiency. Exosome molecular and nanoengineering will provide insights into future effective and precision medicine for devastating diseases such as neurodegenerative disorders. Because targeted exosomal delivery is a rapidly developing field, aptamer-mediated exosomal delivery is becoming appealing for 
the development of smart nano-delivery systems due to its ease of use, high performance at the nanoscale, enhanced efficacy, safety, and low cost [173,174].

Although preclinical studies have provided the biological and mechanistic foundation for previous clinical trials, future efforts to improve the predictive accuracy of preclinical studies will be critical to clinical trial success. To improve clinical translation, health experts hope to develop research guidelines such as the Stroke Therapy Academic Industry Roundtable (STAIR) recommendations. The Federal Interagency Traumatic Brain Injury Research (FITBIR) system was designed to share TBI-related research across the research community [175]. Future efforts for the development of nanomaterials to treat acute brain injuries include accurate measurement of nanomaterial pharmacokinetics in living organisms, careful selection of animal models that recapitulate specific human pathology relevant to nanomaterial design and payload, designing experiments that consider multiple biological variables, and the development of technology to quantitatively measure biomarkers that can accurately predict outcomes in humans.

\title{
10. Conclusions
}

Nanotechnology can alter neuroscience-based information and restorative methodologies, and can be used to possibly make significant commitments for the development of nano-empowered medication for the treatment of NDs. Equal advancements in neurophysiology and neuropathology exploration would help in the advancement in nanotechnology, which can be used to provide CNS recovery and neuroprotection. Accordingly, for utilization of nanotechnology in neural system science and neurosurgery, key factors that require consideration include: (1) breakthrough discoveries and developments in drug science and material science, which can help in the manufacturing of the described methodologies; (2) development and advancement of sub-atomic science, sensory system-based neurophysiology, and neuropathology; and (3) planning and combination of explicit nano-empowered therapies to the CNS, which exploit the initial two factors. As a result, nanotechnology could provide the solution and can offer breakthrough therapies for the management and treatment of NDs and can also be used to bypass the current problem of available neurological therapies i.e., non-specific targeting and lower efficacy rates of drug therapies. Therefore, taken together, neurosurgeons, nervous system specialists, neuroscientists, and drug researchers and architects, should take part in utilizing the power of nanotechnology for drug delivery. Consistent with the profoundly interdisciplinary nature of this space of exploration, it is additionally significant to note that nano-informatics and nanotechnology can also provide innovative headways and progressions that are related to fundamental and clinical neuroscience.

Author Contributions: Conceptualization, T.B.; data curation, T.B. and G.A.B.e.S.; writing-original draft preparation, T.B., G.A.B.e.S., H.C., M.M.R., Z.H. and S.S.S.; validation, T.B. and G.A.B.e.S.; formal analysis, T.B., G.A.B.e.S., H.C., M.M.R., Z.H., S.S.S. and S.C.; investigation, T.B., G.A.B.e.S. and S.C.; resources, T.B.; writing-reviewing and editing, T.B., G.A.B.e.S. and S.C.; visualization, T.B., G.A.B.e.S., H.C.,M.M.R., Z.H., S.S.S. and S.C.; supervision, T.B. and S.C.; project administration, T.B. and S.C. All authors have read and agreed to the published version of the manuscript.

Funding: This research received no external founds.

Conflicts of Interest: The authors declare no conflict of interest.

\author{
Abbreviations \\ BBB Blood brain barrier \\ CNS Central nervous system \\ ND Neurological and neurodegenerative diseases \\ NP Nanoparticle \\ AD Alzheimer's disease \\ PD Parkinson's disease
}




$\begin{array}{ll}\text { ALS } & \text { Amyotrophic horizontal sclerosis } \\ \text { JNK } & \text { c-Jun N-terminal kinase } \\ \text { AChE } & \text { Acetylcholinesterase } \\ \text { IC50 } & \text { Half-maximal inhibitory concentration } \\ \text { SAC } & \text { S-allyl cysteine } \\ \text { MPP } & \text { Phenyl pyridinium } \\ \text { SOD } & \text { Superoxide dismutase } \\ \text { 6-OHDA } & \text { 6-hydroxydopamine } \\ \text { CAT } & \text { Chloramphenicol acetyltransferase } \\ \text { GPx } & \text { Gluthathione peroxidase } \\ \text { GPR } & \text { Glutathione reductase } \\ \text { ATP } & \text { Adenosine triphosphate } \\ \text { iNOS } & \text { Inducible nitric oxide synthase } \\ \text { COX-2: } & \text { Cyclo-oxygenase 2 } \\ \text { MDA } & \text { Malondialdehyde } \\ \text { GSH } & \text { Glutathione } \\ \text { CPPME } & \text { Celastrus paniculate wild whole plant methanolic extract } \\ \text { LPO } & \text { Lipid peroxidation } \\ \text { DPPH } & \text { 2,2-diphenyl-1-picrylhydrazyl } \\ \text { GABA } & \text { Gamma- amino butyric acid } \\ \text { MAO } & \text { Monoamine oxidases } \\ \text { DNA } & \text { Deoxyribo nucleic acid } \\ \text { mRNA } & \text { Messenger ribonucleic acid } \\ \text { 5-HT } & \text { 5-hydroxytrptamine/serotonin } \\ \text { DA } & \text { Dopamine } \\ \text { ROS } & \text { Reactive oxygen species } \\ \text { VMAT } & \text { Vesicular monoamine transporter } \\ \text { NMDA } & \text { N-methyl-D-aspartic acid } \\ \text { COMT } & \text { Catechol ortho-methyl transferase } \\ \text { CSF } & \text { Cerebrospinal fluid } \\ \text { PET } & \text { Positron emission tomography } \\ \text { SPECT } & \text { Single photon emission computed tomography } \\ \text { NIH } & \text { National Institute of Health } \\ \text { NSF } & \text { National Science Foundation } \\ \text { USFDA } & \text { United States Food and Drug Administration } \\ \text { STAIR } & \text { Stroke Therapy Academic Industry Roundtable } \\ \text { FITBIR } & \text { Federal Interagency Traumatic Brain Injury Research } \\ & \end{array}$

\section{References}

1. Bensadoun, J.-C.; Almeida, L.P.d.; Fine, E.G.; Tseng, J.L.; Déglon, N.; Aebischer, P. Comparative study of GDNF delivery systems for the CNS: Polymer rods, encapsulated cells, and lentiviral vectors. J. Control. Release 2003, 87, 107-115. [CrossRef]

2. Kishima, H.; Poyot, T.; Bloch, J.; Dauguet, J.; Conde, F.; Dolle, F.; Hinnen, F.; Pralong, W.; Palfi, S.; Deglon, N.; et al. Encapsulated GDNF-producing C2C12 cells for Parkinson's disease: A pre-clinical study in chronic MPTP-treated baboons. Neurobiol. Dis. 2004, 16, 428-439. [CrossRef]

3. McArthur, J.C. HIV dementia: An evolving disease. J. Neuroimmunol. 2004, 157, 3-10. [CrossRef] [PubMed]

4. Menei, P.; Montero-Menei, C.; Venier, M.C.; Benoit, J.P. Drug delivery into the brain using poly(lactide-co-glycolide) microspheres. Expert Opin. Drug Deliv. 2005, 2, 363-376. [CrossRef] [PubMed]

5. Flachenecker, P. Epidemiology of neuroimmunological diseases. J. Neurol. 2006, 253 (Suppl. 5), V2-V8. [CrossRef]

6. Kabanov, A.V.; Gendelman, H.E. Nanomedicine in the diagnosis and therapy of neurodegenerative disorders. Prog. Polym. Sci. 2007, 32, 1054-1082. [CrossRef]

7. Ferri, C.P.; Prince, M.; Brayne, C.; Brodaty, H.; Fratiglioni, L.; Ganguli, M.; Hall, K.; Hasegawa, K.; Hendrie, H.; Huang, Y.; et al. Global prevalence of dementia: A Delphi consensus study. Lancet 2005, 366, 2112-2117. [CrossRef]

8. Popovic, N.; Brundin, P. Therapeutic potential of controlled drug delivery systems in neurodegenerative diseases. Int. J. Pharm. 2006, 314, 120-126. [CrossRef]

9. Singh, N.; Pillay, V.; Choonara, Y.E. Advances in the treatment of Parkinson's disease. Prog. Neurobiol. 2007, 81, 29-44. [CrossRef]

10. Tysnes, O.B.; Storstein, A. Epidemiology of Parkinson's disease. J. Neura. Transm. (Vienna) 2017, 124, 901-905. [CrossRef] 
11. Freed, C.R.; Greene, P.E.; Breeze, R.E.; Tsai, W.Y.; DuMouchel, W.; Kao, R.; Dillon, S.; Winfield, H.; Culver, S.; Trojanowski, J.Q.; et al. Transplantation of embryonic dopamine neurons for severe Parkinson's disease. N. Engl. J. Med. 2001, 344, 710-719. [CrossRef] [PubMed]

12. Pollak, P.; Fraix, V.; Krack, P.; Moro, E.; Mendes, A.; Chabardes, S.; Koudsie, A.; Benabid, A.-L. Treatment results: Parkinson's disease. Mov. Disord. 2002, 17, S75-S83. [CrossRef] [PubMed]

13. Johnson, W.G. Late-onset neurodegenerative diseases-The role of protein insolubility. J. Anat. 2000, 196 Pt 4, $609-616$. [CrossRef] [PubMed]

14. Dickson, D.W. Misfolded, protease-resistant proteins in animal models and human neurodegenerative disease. J. Clin. Investig. 2002, 110, 1403-1405. [CrossRef]

15. Woodruff, B.K.; Graff-Radford, N.R.; Ferman, T.J.; Dickson, D.W.; DeLucia, M.W.; Crook, J.E.; Arvanitakis, Z.; Brassler, S.; Waters, C.; Barker, W.; et al. Family history of dementia is a risk factor for Lewy body disease. Neurology 2006, 66, 1949-1950. [CrossRef]

16. Walia, V.; Kaushik, D.; Mittal, V.; Kumar, K.; Verma, R.; Parashar, J.; Akter, R.; Rahman, M.H.; Bhatia, S.; Al-Harrasi, A.; et al. Delineation of Neuroprotective Effects and Possible Benefits of AntioxidantsTherapy for the Treatment of Alzheimer's Diseases by Targeting Mitochondrial-Derived Reactive Oxygen Species: Bench to Bedside. Mol. Neurobiol. 2021. [CrossRef]

17. Nischwitz, V.; Berthele, A.; Michalke, B. Speciation analysis of selected metals and determination of their total contents in paired serum and cerebrospinal fluid samples: An approach to investigate the permeability of the human blood-cerebrospinal fluid-barrier. Anal. Chim. Act. 2008, 627, 258-269. [CrossRef]

18. Gendelman, H.E.; Ding, S.; Gong, N.; Liu, J.; Ramirez, S.H.; Persidsky, Y.; Mosley, R.L.; Wang, T.; Volsky, D.J.; Xiong, H. Monocyte chemotactic protein-1 regulates voltage-gated $\mathrm{K}+$ channels and macrophage transmigration. J. Neuroimmune Pharm. 2009, 4, 47-59. [CrossRef]

19. Modi, G.; Pillay, V.; Choonara, Y.E.; Ndesendo, V.M.; du Toit, L.C.; Naidoo, D. Nanotechnological applications for the treatment of neurodegenerative disorders. Prog. Neurobiol. 2009, 88, 272-285. [CrossRef]

20. Page, M.J.; McKenzie, J.E.; Bossuyt, P.M.; Boutron, I.; Hoffmann, T.C.; Mulrow, C.D.; Shamseer, L.; Tetzlaff, J.M.; Moher, D. Updating guidance for reporting systematic reviews: Development of the PRISMA 2020 statement. J. Clin. Epidemiol. 2021, 134, 103-112. [CrossRef]

21. Page, M.J.; McKenzie, J.E.; Bossuyt, P.M.; Boutron, I.; Hoffmann, T.C.; Mulrow, C.D.; Shamseer, L.; Tetzlaff, J.M.; Akl, E.A.; Brennan, S.E.; et al. The PRISMA 2020 statement: An updated guideline for reporting systematic reviews. J. Clin. Epidemiol. 2021, 134, 178-189. [CrossRef]

22. Kim, J.; Mook-Jung, I. Special issue on neurodegenerative diseases and their therapeutic approaches. Exp. Mol. Med. 2015, 47, e146. [CrossRef]

23. Ballabh, P.; Braun, A.; Nedergaard, M. The blood-brain barrier: An overview: Structure, regulation, and clinical implications. Neurobiol. Dis. 2004, 16, 1-13. [CrossRef]

24. Abbott, N.J.; Patabendige, A.A.; Dolman, D.E.; Yusof, S.R.; Begley, D.J. Structure and function of the blood-brain barrier. Neurobiol. Dis. 2010, 37, 13-25. [CrossRef]

25. Silva, G.A. Neuroscience nanotechnology: Progress, opportunities and challenges. Nat. Rev. Neurosci. 2006, 7, 65-74. [CrossRef]

26. Moghimi, S.M.; Hunter, A.C.; Murray, J.C. Nanomedicine: Current status and future prospects. FASEB J. 2005, 19, 311-330. [CrossRef]

27. Goldsmith, M.; Abramovitz, L.; Peer, D. Precision nanomedicine in neurodegenerative diseases. ACS Nano 2014, 8, 1958-1965. [CrossRef] [PubMed]

28. Illum, L. Nasal drug delivery-Possibilities, problems and solutions. J. Control. Release 2003, 87, 187-198. [CrossRef]

29. Pardridge, W.M. CSF, blood-brain barrier, and brain drug delivery. Expert Opin. Drug Deliv. 2016, 13, 963-975. [CrossRef] [PubMed]

30. McDannold, N.; Arvanitis, C.D.; Vykhodtseva, N.; Livingstone, M.S. Temporary disruption of the blood-brain barrier by use of ultrasound and microbubbles: Safety and efficacy evaluation in rhesus macaques. Cancer Res. 2012, 72, $3652-3663$. [CrossRef] [PubMed]

31. Dasgupta, A.; Liu, M.; Ojha, T.; Storm, G.; Kiessling, F.; Lammers, T. Ultrasound-mediated drug delivery to the brain: Principles, progress and prospects. Drug Discov. Today Technol. 2016, 20, 41-48. [CrossRef]

32. Cheng, Z.; Zhang, J.; Liu, H.; Li, Y.; Zhao, Y.; Yang, E. Central nervous system penetration for small molecule therapeutic agents does not increase in multiple sclerosis- and Alzheimer's disease-related animal models despite reported blood-brain barrier disruption. Drug Metab. Dispos. 2010, 38, 1355-1361. [CrossRef] [PubMed]

33. Roy Chowdhury, S.; Mondal, S.; Muthuraj, B.; Balaji, S.N.; Trivedi, V.; Krishnan Iyer, P. Remarkably Efficient Blood-Brain Barrier Crossing Polyfluorene-Chitosan Nanoparticle Selectively Tweaks Amyloid Oligomer in Cerebrospinal Fluid and Abeta1-40. ACS Omega 2018, 3, 8059-8066. [CrossRef] [PubMed]

34. Cavalu, S.; Damian, G. Rotational Correlation Times of 3-Carbamoyl-2,2,5,5-Tetramethyl-3-Pyrrolin-1-Yloxy Spin Label with Respect to Heme and Nonheme Proteins. Biomacromolecules 2003, 4, 1630-1635. [CrossRef] [PubMed]

35. Kaushik, A.C.; Kumar, A.; Peng, Z.; Khan, A.; Junaid, M.; Ali, A.; Bharadwaj, S.; Wei, D.-Q. Evaluation and validation of synergistic effects of amyloid-beta inhibitor-gold nanoparticles complex on Alzheimer's disease using deep neural network approach. J. Mater. Res. 2019, 34, 1845-1853. [CrossRef]

36. Choi, C.H.; Alabi, C.A.; Webster, P.; Davis, M.E. Mechanism of active targeting in solid tumors with transferrin-containing gold nanoparticles. Proc. Natl. Acad. Sci. USA 2010, 107, 1235-1240. [CrossRef] [PubMed] 
37. Kong, S.D.; Lee, J.; Ramachandran, S.; Eliceiri, B.P.; Shubayev, V.I.; Lal, R.; Jin, S. Magnetic targeting of nanoparticles across the intact blood-brain barrier. J. Control. Release 2012, 164, 49-57. [CrossRef]

38. Smith, M.W.; Gumbleton, M. Endocytosis at the blood-brain barrier: From basic understanding to drug delivery strategies. J. Drug Target. 2006, 14, 191-214. [CrossRef]

39. Fessi, H.; Puisieux, F.; Devissaguet, J.P.; Ammoury, N.; Benita, S. Nanocapsule formation by interfacial polymer deposition following solvent displacement. Int. J. Pharm. 1989, 55, R1-R4. [CrossRef]

40. Mora-Huertas, C.E.; Fessi, H.; Elaissari, A. Influence of process and formulation parameters on the formation of submicron particles by solvent displacement and emulsification-diffusion methods critical comparison. Adv. Colloid. Interface Sci. 2011, 163, 90-122. [CrossRef]

41. Cavalu, S.; Bisboaca, S.; Mates, I.M.; Pasca, P.M.; Laslo, V.; Costea, T.; Fritea, L.; Vicas, S. Novel Formulation Based on ChitosanArabic Gum Nanoparticles Entrapping Propolis Extract Production, physico-chemical and structural characterization. Rev. Chim. 2018, 69, 3756-3760. [CrossRef]

42. Erdogar, N.; Akkin, S.; Bilensoy, E. Nanocapsules for Drug Delivery: An Updated Review of the Last Decade. Recent Pat. Drug Deliv. Formul. 2018, 12, 252-266. [CrossRef] [PubMed]

43. Niwa, T.; Takeuchi, H.; Hino, T.; Kunou, N.; Kawashima, Y. Preparations of biodegradable nanospheres of water-soluble and insoluble drugs with D,L-lactide/glycolide copolymer by a novel spontaneous emulsification solvent diffusion method, and the drug release behavior. J. Control. Release 1993, 25, 89-98. [CrossRef]

44. Murakami, H.; Kobayashi, M.; Takeuchi, H.; Kawashima, Y. Preparation of poly(dl-lactide-co-glycolide) nanoparticles by modified spontaneous emulsification solvent diffusion method. Int. J. Pharm. 1999, 187, 143-152. [CrossRef]

45. Quintanar-Guerrero, D.; Allemann, E.; Fessi, H.; Doelker, E. Pseudolatex preparation using a novel emulsion-diffusion process involving direct displacement of partially water-miscible solvents by distillation. Int. J. Pharm. 1999, 188, 155-164. [CrossRef]

46. Yusuf, M.; Khan, M.; Khan, R.A.; Ahmed, B. Preparation, characterization, in vivo and biochemical evaluation of brain targeted Piperine solid lipid nanoparticles in an experimentally induced Alzheimer's disease model. J. Drug Target. 2013, $21,300-311$. [CrossRef] [PubMed]

47. McCall, R.L.; Sirianni, R.W. PLGA nanoparticles formed by single- or double-emulsion with vitamin E-TPGS. J. Vis. Exp. 2013, 82, 51015. [CrossRef]

48. Huang, W.; Zhang, C. Tuning the Size of Poly(lactic-co-glycolic Acid) (PLGA) Nanoparticles Fabricated by Nanoprecipitation Biotechnol. J. 2018, 13, 1700203. [CrossRef] [PubMed]

49. Cavalu, S.; Prokisch, J.; Laslo, V.; Vicas, S. Preparation, structural characterisation and release study of novel hybrid microspheres entrapping nanoselenium, produced by green synthesis. IET Nanobiotechnol. 2017, 11, 426-432. [CrossRef]

50. Tarhini, M.; Greige-Gerges, H.; Elaissari, A. Protein-based nanoparticles: From preparation to encapsulation of active molecules. Int. J. Pharm. 2017, 522, 172-197. [CrossRef]

51. Zhang, D.; Ma, X.L.; Gu, Y.; Huang, H.; Zhang, G.W. Green Synthesis of Metallic Nanoparticles and Their Potential Applications to Treat Cancer. Front. Chem. 2020, 8, 799. [CrossRef] [PubMed]

52. Cavalu, S.; Antoniac, I.V.; Mohan, A.; Bodog, F.; Doicin, C.; Mates, I.; Ulmeanu, M.; Murzac, R.; Semenescu, A. Nanoparticles and Nanostructured Surface Fabrication for Innovative Cranial and Maxillofacial Surgery. Materials 2020, 13, 5391. [CrossRef]

53. Velmurugan, B.K.; Rathinasamy, B.; Lohanathan, B.P.; Thiyagarajan, V.; Weng, C.F. Neuroprotective Role of Phytochemicals. Molecules 2018, 23, 2485. [CrossRef]

54. Xu, J.; Wold, E.A.; Ding, Y.; Shen, Q.; Zhou, J. Therapeutic Potential of Oridonin and Its Analogs: From Anticancer and Antiinflammation to Neuroprotection. Molecules 2018, 23, 474. [CrossRef]

55. Hajialyani, M.; Hosein Farzaei, M.; Echeverria, J.; Nabavi, S.M.; Uriarte, E.; Sobarzo-Sanchez, E. Hesperidin as a Neuroprotective Agent: A Review of Animal and Clinical Evidence. Molecules 2019, 24, 648. [CrossRef] [PubMed]

56. Tripathy, N.; Ahmad, R.; Khang, G. Inorganic Nanotheranostics: Strategy development and applications. Drug Deliv. Nanosyst. Biomed. Appl. 2018, 377-419. [CrossRef]

57. Bar-Zeev, M.; Livney, Y.D.; Assaraf, Y.G. Targeted nanomedicine for cancer therapeutics: Towards precision medicine overcoming drug resistance. Drug Resist. Updat. 2017, 31, 15-30. [CrossRef]

58. Lausanne, E.P.F.D. On the Way to Nanotheranostics: Diagnosing and Treating Diseases Simultaneously. Available online: www.sciencedaily.com/releases/2019/07/190708131203.htm (accessed on 15 May 2021).

59. Bandelow, B.; Michaelis, S.; Wedekind, D. Treatment of anxiety disorders. Dialogues. Clin. Neurosci. 2017, $19,93-107$.

60. Powell, C.R.; Dillon, K.M.; Matson, J.B. A review of hydrogen sulfide (H2S) donors: Chemistry and potential therapeutic applications. Biochem. Pharmacol. 2018, 149, 110-123. [CrossRef] [PubMed]

61. Shang, A.; Cao, S.Y.; Xu, X.Y.; Gan, R.Y.; Tang, G.Y.; Corke, H.; Mavumengwana, V.; Li, H.B. Bioactive Compounds and Biological Functions of Garlic (Allium sativum L.). Foods 2019, 8, 246. [CrossRef]

62. Chen, X.; Pan, W. The treatment strategies for neurodegenerative diseases by integrative medicine. Integr. Med. Int. 2014, 1, 223-225. [CrossRef]

63. Roy, S.; Awasthi, H. Herbal medicines as neuroprotective agent: A mechanistic approach. Int. J. Pharm. Pharm. Sci. 2017, 9, 1-7. [CrossRef]

64. Chopra, H.; Dey, P.S.; Das, D.; Bhattacharya, T.; Shah, M.; Mubin, S.; Maishu, S.P.; Akter, R.; Rahman, M.H.; Karthika, C.; et al. Curcumin Nanoparticles as Promising Therapeutic Agents for Drug Targets. Molecules 2021, 26, 4998. [CrossRef] [PubMed] 
65. Soares, G.A.B.e.; Bhattacharya, T.; Chakrabarti, T.; Tagde, P.; Cavalu, S. Exploring Pharmacological Mechanisms of Essential Oils on the Central Nervous System. Plants 2021, 11, 21. [CrossRef]

66. Jakka, A. A Study on Nootropic Activity of Celastrus Paniculata Willd Whole Plant Methanolic Extract in Rats. Asian J. Pharm. Clin. Res. 2016, 9, 336-341.

67. Amadi, C.N.; Offor, S.J.; Frazzoli, C.; Orisakwe, O.E. Natural antidotes and management of metal toxicity. Environ. Sci. Pollut. Res. Int. 2019, 26, 18032-18052. [CrossRef]

68. Ashraf, A.; Zafar, S.; Zahid, K.; Salahuddin Shah, M.; Al-Ghanim, K.A.; Al-Misned, F.; Mahboob, S. Synthesis, characterization, and antibacterial potential of silver nanoparticles synthesized from Coriandrum sativum L. J. Infect. Public Health 2019, 12, 275-281. [CrossRef]

69. Owoeye, O.; Obazie, F.I.; Atiba, F.A.; Malomo, A.O. Comparative Neuroprotective Effect of Celosia argentea Linn. and Vitamin E on Mercury-induced Oxidative and Histological Parameters of Rat Brain. Niger. J. Physiol. Sci. 2019, 34, 167-175.

70. Yang, S.; Chang, M.C. Chronic Pain: Structural and Functional Changes in Brain Structures and Associated Negative Affective States. Int. J. Mol. Sci. 2019, 20, 3130. [CrossRef]

71. Yuan, Q.; Wang, C.W.; Shi, J.; Lin, Z.X. Effects of Ginkgo biloba on dementia: An overview of systematic reviews. J. Ethnopharmacol. 2017, 195, 1-9. [CrossRef] [PubMed]

72. Abdolmaleki, A.; Akram, M.; Saeed, M.M.; Asadi, A.; Kajkolah, M. Herbal medicine as neuroprotective potential agent in human and animal models: A historical overview. J. Pharm. Care 2020, 8, 75-82. [CrossRef]

73. Bridi, H.; Meirelles, G.C.; von Poser, G.L. Structural diversity and biological activities of phloroglucinol derivatives from Hypericum species. Phytochemistry 2018, 155, 203-232. [CrossRef]

74. Agatonovic-Kustrin, S.; Kettle, C.; Morton, D.W. A molecular approach in drug development for Alzheimer's disease. Biomed. Pharm. 2018, 106, 553-565. [CrossRef]

75. Eudes, J.F.; Silveria, D.; Soares, A.C.; Carneiro, F.P.; de Assis, M.S.; Leite, F.B.; Niraldo, P.; Greice, M.S.; Mônica, V.d.S.; Stéphanie, M.; et al. Effects of lemon balm (Melissa officinalis) on behavioral deficits and memory impairment of rats surviving sepsis. J. Med. Plants Res. 2017, 11, 153-160. [CrossRef]

76. Kusindarta, D.L.; Wihadmadyatami, H.; Jadi, A.R.; Karnati, S.; Lochnit, G.; Hening, P.; Haryanto, A.; Auriva, M.B.; Purwaningrum, M. Ethanolic extract Ocimum sanctum. Enhances cognitive ability from young adulthood to middle aged mediated by increasing choline acetyl transferase activity in rat model. Res. Vet. Sci. 2018, 118, 431-438. [CrossRef] [PubMed]

77. Antonescu Mintas, A.I.; Miere Groza, F.; Fritea, L.; Ganea, M.; Zdrinca, M.; Dobjanschi, L.; Antonescu, A.; Vicas, S.I.; Bodog, F.; Sindhu, R.K.; et al. Perspectives on the Combined Effects of Ocimum basilicum and Trifolium pratense Extracts in Terms of Phytochemical Profile and Pharmacological Effects. Plants 2021, 10, 1390. [CrossRef]

78. Ahuja, A.; Kim, J.H.; Kim, J.H.; Yi, Y.S.; Cho, J.Y. Functional role of ginseng-derived compounds in cancer. J. Ginseng Res. 2018, 42, 248-254. [CrossRef]

79. Nieto, G.; Ros, G.; Castillo, J. Antioxidant and Antimicrobial Properties of Rosemary (Rosmarinus officinalis, L.): A Review. Medicines 2018, 5, 98. [CrossRef]

80. Lopresti, A.L. Salvia (Sage): A Review of its Potential Cognitive-Enhancing and Protective Effects. Drugs R D 2017, 17, 53-64. [CrossRef]

81. Lee, D.Y.; Kim, H.W.; Yang, H.; Sung, S.H. Hydrolyzable tannins from the fruits of Terminalia chebula Retz and their alphaglucosidase inhibitory activities. Phytochemistry 2017, 137, 109-116. [CrossRef] [PubMed]

82. Tiwari, P.; Nayak, P.; Prusty, S.K.; Sahu, P.K. Phytochemistry and pharmacology of Tinospora cordifolia: A review. Syst. Rev. Pharm. 2018, 9, 70-78. [CrossRef]

83. RajaSankar, S.; Manivasagam, T.; Sankar, V.; Prakash, S.; Muthusamy, R.; Krishnamurti, A.; Surendran, S. Withania somnifera root extract improves catecholamines and physiological abnormalities seen in a Parkinson's disease model mouse. J. Ethnopharmacol. 2009, 125, 369-373. [CrossRef]

84. Olasehinde, T.A.; Olaniran, A.O.; Okoh, A.I. Therapeutic Potentials of Microalgae in the Treatment of Alzheimer's Disease. Molecules 2017, 22, 480. [CrossRef]

85. Stone, N.L.; Murphy, A.J.; England, T.J.; O'Sullivan, S.E. A systematic review of minor phytocannabinoids with promising neuroprotective potential. Br. J. Pharmacol. 2020, 177, 4330-4352. [CrossRef]

86. Wyant, K.J.; Ridder, A.J.; Dayalu, P. Huntington's Disease-Update on Treatments. Curr. Neurol. Neurosci. Rep. 2017, 17, 33. [CrossRef] [PubMed]

87. Hussain, G.; Rasul, A.; Anwar, H.; Aziz, N.; Razzaq, A.; Wei, W.; Ali, M.; Li, J.; Li, X. Role of Plant Derived Alkaloids and Their Mechanism in Neurodegenerative Disorders. Int. J. Biol. Sci. 2018, 14, 341-357. [CrossRef] [PubMed]

88. Kumar, A.; Chaudhary, R.K.; Singh, R.; Singh, S.P.; Wang, S.Y.; Hoe, Z.Y.; Pan, C.T.; Shiue, Y.L.; Wei, D.Q.; Kaushik, A.C.; et al. Nanotheranostic Applications for Detection and Targeting Neurodegenerative Diseases. Front. Neurosci. 2020, 14, 305. [CrossRef]

89. Khalil, A.T.; Ovais, M.; Ullah, I.; Ali, M.; Shinwari, Z.K.; Khamlich, S.; Maaza, M. Sageretia thea (Osbeck.) mediated synthesis of zinc oxide nanoparticles and its biological applications. Nanomedicine 2017, 12, 1767-1789. [CrossRef] [PubMed]

90. Ovais, M.; Zia, N.; Ahmad, I.; Khalil, A.T.; Raza, A.; Ayaz, M.; Sadiq, A.; Ullah, F.; Shinwari, Z.K. Phyto-Therapeutic and Nanomedicinal Approaches to Cure Alzheimer's Disease: Present Status and Future Opportunities. Front. Aging Neurosci 2018, 10, 284. [CrossRef] 
91. Ovais, M.; Nadhman, A.; Khalil, A.T.; Raza, A.; Khuda, F.; Sohail, M.F.; Islam, N.U.; Sarwar, H.S.; Shahnaz, G.; Ahmad, I.; et al. Biosynthesized colloidal silver and gold nanoparticles as emerging leishmanicidal agents: An insight. Nanomedicine 2017, 12, 2807-2819. [CrossRef] [PubMed]

92. Gaude, T.T.; Soares, G.A.B.e.; Priolkar, R.N.S.; Biradar, B.; Mamledesai, S. Synthesis of 4-hydroxy-1-(phenyl/methyl)-3-[3(substituted amino)-2-nitropropanoyl] quinolin-2(1H)-ones as an antimicrobial andantitubercular agents. Indian J. Heterocycl. Chem. 2017, 27, 223-228.

93. Emmanuel, R.; Saravanan, M.; Ovais, M.; Padmavathy, S.; Shinwari, Z.K.; Prakash, P. Antimicrobial efficacy of drug blended biosynthesized colloidal gold nanoparticles from Justicia glauca against oral pathogens: A nanoantibiotic approach. Microb. Pathog. 2017, 113, 295-302. [CrossRef]

94. Suganthy, N.; Sri Ramkumar, V.; Pugazhendhi, A.; Benelli, G.; Archunan, G. Biogenic synthesis of gold nanoparticles from Terminalia arjuna bark extract: Assessment of safety aspects and neuroprotective potential via antioxidant, anticholinesterase, and antiamyloidogenic effects. Environ. Sci. Pollut. Res. Int. 2018, 25, 10418-10433. [CrossRef] [PubMed]

95. Reddy, P.H.; Manczak, M.; Yin, X.; Grady, M.C.; Mitchell, A.; Tonk, S.; Kuruva, C.S.; Bhatti, J.S.; Kandimalla, R.; Vijayan, M.; et al. Protective Effects of Indian Spice Curcumin against Amyloid-beta in Alzheimer's Disease. J. Alzheimers. Dis. 2018, 61, 843-866. [CrossRef] [PubMed]

96. Yusuf, M.; Khan, M.; Alrobaian, M.M.; Alghamdi, S.A.; Warsi, M.H.; Sultana, S.; Khan, R.A. Brain targeted Polysorbate-80 coated PLGA thymoquinone nanoparticles for the treatment of Alzheimer's disease, with biomechanistic insights. J. Drug Deliv. Sci. Technol. 2021, 61, 102214. [CrossRef]

97. Xu, R.; Wang, J.; Xu, J.; Song, X.; Huang, H.; Feng, Y.; Fu, C. Rhynchophylline Loaded-mPEG-PLGA Nanoparticles Coated with Tween-80 for Preliminary Study in Alzheimer's Disease. Int. J. Nanomed. 2020, 15, 1149-1160. [CrossRef]

98. Jacob, J.; Haponiuk, J.T.; Thomas, S.; Gopi, S. Biopolymer based nanomaterials in drug delivery systems: A Review. Mater. Today Chem. 2018, 9, 43-55. [CrossRef]

99. Numata, K.; Kaplan, D.L. Silk-based delivery systems of bioactive molecules. Adv. Drug Deliv. Rev. 2010, 62, 1497-1508. [CrossRef]

100. Chopra, H.; Kumar, S.; Singh, I. Biopolymer-based Scaffolds for Tissue Engineering Applications. Curr. Drug Targets 2021, 22, 282-295. [CrossRef]

101. Langer, K.; Balthasar, S.; Vogel, V.; Dinauer, N.; Briesen, H.v.; Schubert, D. Optimization of the preparation process for human serum albumin (HSA) nanoparticles. Int. J. Pharm. 2003, 257, 169-180. [CrossRef]

102. Jahanban-Esfahlan, A.; Dastmalchi, S.; Davaran, S. A simple improved desolvation method for the rapid preparation of albumin nanoparticles. Int. J. Biol. Macromol. 2016, 91, 703-709. [CrossRef]

103. Kratz, F. Albumin as a drug carrier: Design of prodrugs, drug conjugates and nanoparticles. J. Control. Release 2008, 132, 171-183. [CrossRef]

104. Sathya, S.; Shanmuganathan, B.; Devi, K.P. Deciphering the anti-apoptotic potential of alpha-bisabolol loaded solid lipid nanoparticles against Abeta induced neurotoxicity in Neuro-2a cells. Colloids Surf. B Biointerfaces 2020, 190, 110948. [CrossRef]

105. Pinheiro, R.G.R.; Granja, A.; Loureiro, J.A.; Pereira, M.C.; Pinheiro, M.; Neves, A.R.; Reis, S. Quercetin lipid nanoparticles functionalized with transferrin for Alzheimer's disease. Eur. J. Pharm. Sci. 2020, 148, 105314. [CrossRef]

106. Giacomeli, R.; Izoton, J.C.; Dos Santos, R.B.; Boeira, S.P.; Jesse, C.R.; Haas, S.E. Neuroprotective effects of curcumin lipid-core nanocapsules in a model Alzheimer's disease induced by beta-amyloid 1-42 peptide in aged female mice. Brain Res. 2019, 1721, 146325. [CrossRef]

107. Mathew, A.; Fukuda, T.; Nagaoka, Y.; Hasumura, T.; Morimoto, H.; Yoshida, Y.; Maekawa, T.; Venugopal, K.; Kumar, D.S Curcumin loaded-PLGA nanoparticles conjugated with Tet-1 peptide for potential use in Alzheimer's disease. PLoS ONE 2012, 7, e32616. [CrossRef]

108. Pinheiro, R.G.R.; Granja, A.; Loureiro, J.A.; Pereira, M.C.; Pinheiro, M.; Neves, A.R.; Reis, S. RVG29-Functionalized Lipid Nanoparticles for Quercetin Brain Delivery and Alzheimer's Disease. Pharm. Res. 2020, 37, 139. [CrossRef]

109. Cano, A.; Ettcheto, M.; Chang, J.H.; Barroso, E.; Espina, M.; Kuhne, B.A.; Barenys, M.; Auladell, C.; Folch, J.; Souto, E.B.; et al Dual-drug loaded nanoparticles of Epigallocatechin-3-gallate (EGCG)/Ascorbic acid enhance therapeutic efficacy of EGCG in a APPswe/PS1dE9 Alzheimer's disease mice model. J. Control. Release 2019, 301, 62-75. [CrossRef] [PubMed]

110. Zhao, Y.; Xiong, S.; Liu, P.; Liu, W.; Wang, Q.; Liu, Y.; Tan, H.; Chen, X.; Shi, X.; Wang, Q.; et al. Polymeric Nanoparticles-Based Brain Delivery with Improved Therapeutic Efficacy of Ginkgolide B in Parkinson's Disease. Int. J. Nanomed. 2020, 15, 10453-10467. [CrossRef] [PubMed]

111. Xue, Y.; Wang, N.; Zeng, Z.; Huang, J.; Xiang, Z.; Guan, Y.-Q. Neuroprotective effect of chitosan nanoparticle gene delivery system grafted with acteoside (ACT) in Parkinson's disease models. J. Mater. Sci. Technol. 2020, 43, 197-207. [CrossRef]

112. Tan, J.P.K.; Voo, Z.X.; Lim, S.; Venkataraman, S.; Ng, K.M.; Gao, S.; Hedrick, J.L.; Yang, Y.Y. Effective encapsulation of apomorphine into biodegradable polymeric nanoparticles through a reversible chemical bond for delivery across the blood-brain barrier. Nanomedicine 2019, 17, 236-245. [CrossRef]

113. Chopra, H.; Kumar, S.; Singh, I. Strategies and Therapies for Wound Healing: A Review. Curr. Drug Targets 2021, 23, 87-98. [CrossRef] [PubMed]

114. Li, J.; Han, Y.; Li, M.; Nie, C. Curcumin Promotes Proliferation of Adult Neural Stem Cells and the Birth of Neurons in Alzheimer's Disease Mice via Notch Signaling Pathway. Cell. Reprogram 2019, 21, 152-161. [CrossRef] [PubMed] 
115. Joshi, S.; Singh-Moon, R.P.; Ellis, J.A.; Chaudhuri, D.B.; Wang, M.; Reif, R.; Bruce, J.N.; Bigio, I.J.; Straubinger, R.M. Cerebral hypoperfusion-assisted intra-arterial deposition of liposomes in normal and glioma-bearing rats. Neurosurgery 2015, 76, 92-100. [CrossRef]

116. Noble, G.T.; Stefanick, J.F.; Ashley, J.D.; Kiziltepe, T.; Bilgicer, B. Ligand-targeted liposome design: Challenges and fundamental considerations. Trends Biotechnol. 2014, 32, 32-45. [CrossRef] [PubMed]

117. Sancini, G.; Gregori, M.; Salvati, E.; Cambianica, I.; Re, F.; Ornaghi, F.; Canovi, M.; Fracasso, C.; Cagnotto, A.; Colombo, M.; et al. Functionalization with TAT-peptide enhances blood-brain barrier crossing in vitro of nanoliposomes carrying a curcuminderivative to bind amyloid- $\beta$ peptide. J. Nanomed. Nanotechnol. 2013, 4, 171. [CrossRef]

118. Mourtas, S.; Lazar, A.N.; Markoutsa, E.; Duyckaerts, C.; Antimisiaris, S.G. Multifunctional nanoliposomes with curcumin-lipid derivative and brain targeting functionality with potential applications for Alzheimer disease. Eur. J. Med. Chem. 2014, 80, 175-183. [CrossRef]

119. Naik, S.R.; Pilgaonkar, V.W.; Panda, V.S. Evaluation of antioxidant activity of Ginkgo biloba phytosomes in rat brain. Phytother. Res. 2006, 20, 1013-1016. [CrossRef] [PubMed]

120. Uchegbu, I.F.; Vyas, S.P. Non-ionic surfactant based vesicles (niosomes) in drug delivery. Int. J. Pharm. 1998, 172, 33-70. [CrossRef]

121. Jin, Y.; Wen, J.; Garg, S.; Liu, D.; Zhou, Y.; Teng, L.; Zhang, W. Development of a novel niosomal system for oral delivery of Ginkgo biloba extract. Int J Nanomed. 2013, 8, 421-430. [CrossRef]

122. Poka, L.P.; Mohan, G.K.; Rao, K.V.; Shanker, K. Neuroprotective Effect of Green Synthesized Iron Oxide Nanoparticles Using Aqueous Extract of Convolvulus Pluricaulis Plant in The Management of Alzheimer's Disease. Phytopathology 2017, 9 , 703-709. [CrossRef]

123. Dehvari, M.; Ghahghaei, A. The effect of green synthesis silver nanoparticles (AgNPs) from Pulicaria undulata on the amyloid formation in alpha-lactalbumin and the chaperon action of alpha-casein. Int. J. Biol. Macromol. 2018, 108, 1128-1139. [CrossRef]

124. Nagamune, T. Biomolecular engineering for nanobio/bionanotechnology. Nano Converg. 2017, 4, 9. [CrossRef]

125. Kaushik, A. Biomedical Nanotechnology Related Grand Challenges and Perspectives. Front. Nanotechnol. 2019, 1. [CrossRef]

126. Maojo, V.; Fritts, M.; Martin-Sanchez, F.; De la Iglesia, D.; Cachau, R.E.; Garcia-Remesal, M.; Crespo, J.; Mitchell, J.A.; Anguita, A.; Baker, N.; et al. Nanoinformatics: Developing new computing applications for nanomedicine. Comput. Sci. Eng. 2012, 94, 521-539. [CrossRef] [PubMed]

127. Heath, J.R. Nanotechnologies for biomedical science and translational medicine. Proc. Natl. Acad. Sci. USA 2015, 112, 14436-14443. [CrossRef]

128. Zlokovic, B.V. Current treatments and therapeutic targets in Alzheimer's disease. Adv. Drug Deliv. Rev. 2002, 54, 1533-1537. [CrossRef]

129. Loera-Valencia, R.; Cedazo-Minguez, A.; Kenigsberg, P.A.; Page, G.; Duarte, A.I.; Giusti, P.; Zusso, M.; Robert, P.; Frisoni, G.B.; Cattaneo, A.; et al. Current and emerging avenues for Alzheimer's disease drug targets. J. Intern. Med. 2019, 286, 398-437. [CrossRef]

130. Cummings, J.; Lee, G.; Ritter, A.; Sabbagh, M.; Zhong, K. Alzheimer's disease drug development pipeline: 2020. Alzheimers Dement. 2020, 6, e12050. [CrossRef]

131. Huang, L.K.; Chao, S.P.; Hu, C.J. Clinical trials of new drugs for Alzheimer disease. J. Biomed. Sci. 2020, 27, 18. [CrossRef]

132. Fu, L.M.; Li, J.T. A systematic review of single chinese herbs for Alzheimer's disease treatment. Evid. Based Complement. Altern. Med. 2011, 2011, 640284. [CrossRef] [PubMed]

133. Banks, W.A.; Greig, N.H. Small molecules as central nervous system therapeutics: Old challenges, new directions, and a philosophic divide. Future Med. Chem. 2019, 11, 489-493. [CrossRef] [PubMed]

134. Grabrucker, A.M.; Ruozi, B.; Belletti, D.; Pederzoli, F.; Forni, F.; Vandelli, M.A.; Tosi, G. Nanoparticle transport across the blood brain barrier. Tissue Barriers 2016, 4, e1153568. [CrossRef] [PubMed]

135. Mulvihill, J.J.; Cunnane, E.M.; Ross, A.M.; Duskey, J.T.; Tosi, G.; Grabrucker, A.M. Drug delivery across the blood-brain barrier: Recent advances in the use of nanocarriers. Nanomedicine 2020, 15, 205-214. [CrossRef]

136. Patra, J.K.; Das, G.; Fraceto, L.F.; Campos, E.V.R.; Rodriguez-Torres, M.D.P.; Acosta-Torres, L.S.; Diaz-Torres, L.A.; Grillo, R.; Swamy, M.K.; Sharma, S.; et al. Nano based drug delivery systems: Recent developments and future prospects. J. Nanobiotechnol. 2018, 16, 71. [CrossRef]

137. Ashish, N.; Bhatt, P.; Toga, A.W. Global Data Sharing in Alzheimer Disease Research. Alzheimer. Dis. Assoc. Disord. 2016, 30, 160-168. [CrossRef]

138. Wang, Z.; Yang, H.; Wu, Z.; Wang, T.; Li, W.; Tang, Y.; Liu, G. In Silico Prediction of Blood-Brain Barrier Permeability of Compounds by Machine Learning and Resampling Methods. ChemMedChem 2018, 13, 2189-2201. [CrossRef]

139. Belmadani, M.; Jacobson, M.; Holmes, N.; Phan, M.; Nguyen, T.; Pavlidis, P.; Rogic, S. VariCarta: A Comprehensive Database of Harmonized Genomic Variants Found in Autism Spectrum Disorder Sequencing Studies. Autism. Res. 2019, 12, 1728-1736. [CrossRef]

140. Shaker, B.; Yu, M.S.; Song, J.S.; Ahn, S.; Ryu, J.Y.; Oh, K.S.; Na, D. LightBBB: Computational prediction model of blood-brain-barrier penetration based on LightGBM. Bioinformatics 2021, 37, 1135-1139. [CrossRef]

141. Wang, C.N.; Wang, Y.J.; Wang, H.; Song, L.; Chen, Y.; Wang, J.L.; Ye, Y.; Jiang, B. The Anti-dementia Effects of Donepezil Involve miR-206-3p in the Hippocampus and Cortex. Biol. Pharm. Bull. 2017, 40, 465-472. [CrossRef]

142. Huang, W.; Li, Z.; Zhao, L.; Zhao, W. Simvastatin ameliorate memory deficits and inflammation in clinical and mouse model of Alzheimer's disease via modulating the expression of miR-106b. Biomed. Pharmacother. 2017, 92, 46-57. [CrossRef] 
143. Li, S.H.; Gao, P.; Wang, L.T.; Yan, Y.H.; Xia, Y.; Song, J.; Li, H.Y.; Yang, J.X. Osthole Stimulated Neural Stem Cells Differentiation into Neurons in an Alzheimer's Disease Cell Model via Upregulation of MicroRNA-9 and Rescued the Functional Impairment of Hippocampal Neurons in APP/PS1 Transgenic Mice. Front. Neurosci. 2017, 11, 340. [CrossRef]

144. Jang, M.; Choi, S.H.; Choi, J.H.; Oh, J.; Lee, R.M.; Lee, N.E.; Cho, Y.J.; Rhim, H.; Kim, H.C.; Cho, I.H.; et al. Ginseng gintonin attenuates the disruptions of brain microvascular permeability and microvascular endothelium junctional proteins in an APPswe/PSEN-1 double-transgenic mouse model of Alphalzheimer's disease. Exp. Ther. Med. 2021, 21, 310. [CrossRef]

145. Shi, R.; Zhang, S.; Cheng, G.; Yang, X.; Zhao, N.; Chen, C. Ginsenoside Rg1 and Acori Graminei Rhizoma Attenuates Neuron Cell Apoptosis by Promoting the Expression of miR-873-5p in Alzheimer's Disease. Neurochem. Res. 2018, 43, 1529-1538. [CrossRef]

146. Caggiu, E.; Paulus, K.; Mameli, G.; Arru, G.; Sechi, G.P.; Sechi, L.A. Differential expression of miRNA 155 and miRNA $146 a$ in Parkinson's disease patients. Eneurologicalsci 2018, 13, 1-4. [CrossRef] [PubMed]

147. Serafin, A.; Foco, L.; Zanigni, S.; Blankenburg, H.; Picard, A.; Zanon, A.; Giannini, G.; Pichler, I.; Facheris, M.F.; Cortelli, P.; et al. Overexpression of blood microRNAs 103a, 30b, and 29a in L-dopa-treated patients with PD. Neurology 2015, 84, 645-653. [CrossRef]

148. Schwienbacher, C.; Foco, L.; Picard, A.; Corradi, E.; Serafin, A.; Panzer, J.; Zanigni, S.; Blankenburg, H.; Facheris, M.F.; Giannini, G.; et al. Plasma and White Blood Cells Show Different miRNA Expression Profiles in Parkinson's Disease. J. Mol. Neurosci. 2017, 62, 244-254. [CrossRef] [PubMed]

149. Alieva, A.; Filatova, E.V.; Karabanov, A.V.; Illarioshkin, S.N.; Limborska, S.A.; Shadrina, M.I.; Slominsky, P.A. miRNA expression is highly sensitive to a drug therapy in Parkinson's disease. Parkinsonism. Relat. Disord. 2015, 21, 72-74. [CrossRef]

150. Waschbisch, A.; Atiya, M.; Linker, R.A.; Potapov, S.; Schwab, S.; Derfuss, T. Glatiramer acetate treatment normalizes deregulated microRNA expression in relapsing remitting multiple sclerosis. PLoS ONE 2011, 6, e24604. [CrossRef] [PubMed]

151. Singh, J.; Deshpande, M.; Suhail, H.; Rattan, R.; Giri, S. Targeted Stage-Specific Inflammatory microRNA Profiling in Urine During Disease Progression in Experimental Autoimmune Encephalomyelitis: Markers of Disease Progression and Drug Response. J. Neuroimmune Pharmacol. 2016, 11, 84-97. [CrossRef] [PubMed]

152. Bergman, P.; Piket, E.; Khademi, M.; James, T.; Brundin, L.; Olsson, T.; Piehl, F.; Jagodic, M. Circulating miR-150 in CSF is a novel candidate biomarker for multiple sclerosis. Neurol. Neuroimmunol. Neuroinflamm. 2016, 3, e219. [CrossRef] [PubMed]

153. Fattahi, M.; Rezaei, N.; Nematalahi, F.S.; Shaygannejad, V.; Fouladi, S.; Karimi, L.; Fathi, F.; Dehghani, L.; Mirmosayyeb, O.; Eskandari, N. MicroRNA-29b variants and MxA expression change during interferon beta therapy in patients with relapsingremitting multiple sclerosis. Mult. Scler. Relat. Disord. 2019, 35, 241-245. [CrossRef]

154. Meira, M.; Sievers, C.; Hoffmann, F.; Derfuss, T.; Kuhle, J.; Kappos, L.; Lindberg, R.L. MiR-126: A novel route for natalizumab action? Mult. Scler. 2014, 20, 1363-1370. [CrossRef] [PubMed]

155. Sievers, C.; Meira, M.; Hoffmann, F.; Fontoura, P.; Kappos, L.; Lindberg, R.L. Altered microRNA expression in B lymphocytes in multiple sclerosis: Towards a better understanding of treatment effects. Clin. Immunol. 2012, 144, 70-79. [CrossRef]

156. Ingwersen, J.; Menge, T.; Wingerath, B.; Kaya, D.; Graf, J.; Prozorovski, T.; Keller, A.; Backes, C.; Beier, M.; Scheffler, M.; et al. Natalizumab restores aberrant miRNA expression profile in multiple sclerosis and reveals a critical role for miR-20b. Ann. Clin. Transl. Neurol. 2015, 2, 43-55. [CrossRef]

157. Michell-Robinson, M.A.; Moore, C.S.; Healy, L.M.; Osso, L.A.; Zorko, N.; Grouza, V.; Touil, H.; Poliquin-Lasnier, L.; Trudelle, A.M.; Giacomini, P.S.; et al. Effects of fumarates on circulating and CNS myeloid cells in multiple sclerosis. Ann. Clin. Transl. Neurol. 2016, 3, 27-41. [CrossRef] [PubMed]

158. Eftekharian, M.M.; Komaki, A.; Mazdeh, M.; Arsang-Jang, S.; Taheri, M.; Ghafouri-Fard, S. Expression Profile of Selected MicroRNAs in the Peripheral Blood of Multiple Sclerosis Patients: A Multivariate Statistical Analysis with ROC Curve to Find New Biomarkers for Fingolimod. J. Mol. Neurosci. 2019, 68, 153-161. [CrossRef] [PubMed]

159. Vaknin-Dembinsky, A.; Charbit, H.; Brill, L.; Abramsky, O.; Gur-Wahnon, D.; Ben-Dov, I.Z.; Lavon, I. Circulating microRNAs as biomarkers for rituximab therapy, in neuromyelitis optica (NMO). J. Neuroinflamm. 2016, 13, 179. [CrossRef]

160. Ebrahimkhani, S.; Beadnall, H.N.; Wang, C.; Suter, C.M.; Barnett, M.H.; Buckland, M.E.; Vafaee, F. Serum Exosome MicroRNAs Predict Multiple Sclerosis Disease Activity after Fingolimod Treatment. Mol. Neurobiol. 2020, 57, 1245-1258. [CrossRef]

161. Fattahi, M.; Eskandari, N.; Sotoodehnejadnematalahi, F.; Shaygannejad, V.; Kazemi, M. Comparison of The Expression of miR-326 between Interferon beta Responders and Non-Responders in Relapsing-Remitting Multiple Sclerosis. Cell J. 2020, 22, 92-95. [CrossRef]

162. De Felice, B.; Mondola, P.; Sasso, A.; Orefice, G.; Bresciamorra, V.; Vacca, G.; Biffali, E.; Borra, M.; Pannone, R. Small noncoding RNA signature in multiple sclerosis patients after treatment with interferon-beta. BMC Med. Genom. $2014,7,26$. [CrossRef] [PubMed]

163. Munoz-Culla, M.; Irizar, H.; Castillo-Trivino, T.; Saenz-Cuesta, M.; Sepulveda, L.; Lopetegi, I.; Lopez de Munain, A.; Olascoaga, J.; Baranzini, S.E.; Otaegui, D. Blood miRNA expression pattern is a possible risk marker for natalizumab-associated progressive multifocal leukoencephalopathy in multiple sclerosis patients. Mult. Scler. 2014, 20, 1851-1859. [CrossRef]

164. Fenoglio, C.; De Riz, M.; Pietroboni, A.M.; Calvi, A.; Serpente, M.; Cioffi, S.M.; Arcaro, M.; Oldoni, E.; Scarpini, E.; Galimberti, D. Effect of fingolimod treatment on circulating miR-15b, miR23a and miR-223 levels in patients with multiple sclerosis. J. Neuroimmunol. 2016, 299, 81-83. [CrossRef] [PubMed]

165. Indrasekara, A.S.D.S.; Wadams, R.C.; Fabris, L. Ligand Exchange on Gold Nanorods: Going Back to the Future. Part. Parcle Syst. Charact. 2014, 31, 819-838. [CrossRef] 
166. de Lau, L.M.; Koudstaal, P.J.; Witteman, J.C.; Hofman, A.; Breteler, M.M. Dietary folate, vitamin B12, and vitamin B6 and the risk of Parkinson disease. Neurology 2006, 67, 315-318. [CrossRef]

167. Kim, J.W.; Galanzha, E.I.; Zaharoff, D.A.; Griffin, R.J.; Zharov, V.P. Nanotheranostics of circulating tumor cells, infections and other pathological features in vivo. Mol. Pharm. 2013, 10, 813-830. [CrossRef]

168. Rahman, M.; Akhter, S.; Ahmad, M.Z.; Ahmad, J.; Addo, R.T.; Ahmad, F.J.; Pichon, C. Emerging advances in cancer nanotheranostics with graphene nanocomposites: Opportunities and challenges. Nanomedicine 2015, 10, 2405-2422. [CrossRef]

169. Li, W.; Luo, R.; Lin, X.; Jadhav, A.D.; Zhang, Z.; Yan, L.; Chan, C.Y.; Chen, X.; He, J.; Chen, C.H.; et al. Remote modulation of neural activities via near-infrared triggered release of biomolecules. Biomaterials 2015, 65, 76-85. [CrossRef]

170. Xue, Y.; Wu, J.; Sun, J. Four types of inorganic nanoparticles stimulate the inflammatory reaction in brain microglia and damage neurons in vitro. Toxicol. Lett. 2012, 214, 91-98. [CrossRef] [PubMed]

171. Sunderland, K.S.; Yang, M.; Mao, C. Phage-Enabled Nanomedicine: From Probes to Therapeutics in Precision Medicine. Angew. Chem. Int. Ed. 2017, 56, 1964-1992. [CrossRef] [PubMed]

172. Soliman, H.M.; Ghonaim, G.A.; Gharib, S.M.; Chopra, H.; Farag, A.K.; Hassanin, M.H.; Nagah, A.; Emad-Eldin, M.; Hashem, N.E.; Yahya, G.; et al. Exosomes in Alzheimer's Disease: From Being Pathological Players to Potential Diagnostics and Therapeutics. Int. J. Mol. Sci. 2021, 22, 794. [CrossRef] [PubMed]

173. Tran, P.H.L.; Xiang, D.; Tran, T.T.D.; Yin, W.; Zhang, Y.; Kong, L.; Chen, K.; Sun, M.; Li, Y.; Hou, Y.; et al. Exosomes and Nanoengineering: A Match Made for Precision Therapeutics. Adv. Mater. 2020, 32, e1904040. [CrossRef] [PubMed]

174. Cavalu, S.; Ratiu, C.; Ponta, O.; Simon, V.; Rugina, D.; Miclaus, V.; Akin, I.; Goller, G. Improving osseointegration of alumina/zirconia ceramic implants by fluoride surface treatment. Dig. J. Nanomater. Bios. 2014, 9, 797-808.

175. Kandell, R.M.; Waggoner, L.E.; Kwon, E.J. Nanomedicine for Acute Brain Injuries: Insight from Decades of Cancer Nanomedicine. Mol. Pharm. 2021, 18, 522-538. [CrossRef] [PubMed] 